\title{
Apoplast proteome reveals that extracellular matrix contributes to multistress response in poplar
}

\author{
Olga Pechanova ${ }^{1 \dagger}$, Chuan-Yu Hsu ${ }^{1 \dagger}$, Joshua P Adams ${ }^{1 \dagger}$, Tibor Pechan ${ }^{2}$, Lindsay Vandervelde ${ }^{1}$, Jenny Drnevich ${ }^{3}$, \\ Sara Jawdy ${ }^{4}$, Ardeshir Adeli ${ }^{5}$, Jeffrey C Suttle ${ }^{6}$, Amanda M Lawrence ${ }^{7}$, Timothy J Tschaplinski ${ }^{4}$, Armand Séguin ${ }^{8}$, \\ Cetin Yuceer ${ }^{1 *}$
}

\begin{abstract}
Background: Riverine ecosystems, highly sensitive to climate change and human activities, are characterized by rapid environmental change to fluctuating water levels and siltation, causing stress on their biological components. We have little understanding of mechanisms by which riverine plant species have developed adaptive strategies to cope with stress in dynamic environments while maintaining growth and development.

Results: We report that poplar (Populus spp.) has evolved a systems level "stress proteome" in the leaf-stem-root apoplast continuum to counter biotic and abiotic factors. To obtain apoplast proteins from P. deltoides, we developed pressure-chamber and water-displacement methods for leaves and stems, respectively. Analyses of 303 proteins and corresponding transcripts coupled with controlled experiments and bioinformatics demonstrate that poplar depends on constitutive and inducible factors to deal with water, pathogen, and oxidative stress. However, each apoplast possessed a unique set of proteins, indicating that response to stress is partly compartmentalized. Apoplast proteins that are involved in glycolysis, fermentation, and catabolism of sucrose and starch appear to enable poplar to grow normally under water stress. Pathogenesis-related proteins mediating water and pathogen stress in apoplast were particularly abundant and effective in suppressing growth of the most prevalent poplar pathogen Melampsora. Unexpectedly, we found diverse peroxidases that appear to be involved in stress-induced cell wall modification in apoplast, particularly during the growing season. Poplar developed a robust antioxidative system to buffer oxidation in stem apoplast.
\end{abstract}

Conclusion: These findings suggest that multistress response in the apoplast constitutes an important adaptive trait for poplar to inhabit dynamic environments and is also a potential mechanism in other riverine plant species.

\section{Background}

Riverine ecosystems, characterized with rapid and dramatic environmental changes caused by fluctuating water levels and siltation, harbor a number of plants, including many species of the fast growing, ecological pioneers such as perennial poplar (Populus spp.; [1-5]). These species have a dramatic influence on ecosystem cycles. However, we have little understanding of how plants have adapted to such dynamic environments and

\footnotetext{
* Correspondence: mcy1@msstate.edu

† Contributed equally

'Department of Forestry, Mississippi State University, Mississippi State, MS 39762 USA

Full list of author information is available at the end of the article
}

cope with a variety of continually changing biotic and abiotic stressors while maintaining growth and development.

Leaves, stems, and roots in plants form an integrated physiological unit that receives stress signals and produces metabolic responses to control whole plant growth and development. Communication within the integrated physiological unit occurs through a continuum of symplast and apoplast [6]. Intracellular space of the symplast is composed of cellular cytoplasm connected through plasmodesmata. Apoplast, on the other hand, constitutes extracellular, aqueous space outside the plasma membrane including cell walls, spaces between cells, and xylem [6-8]. Thus, the apoplast
C Biomed Central

(c) 2010 Pechanova et al; licensee BioMed Central Ltd. This is an Open Access article distributed under the terms of the Creative Commons Attribution License (http://creativecommons.org/licenses/by/2.0), which permits unrestricted use, distribution, and reproduction in any medium, provided the original work is properly cited. 
represents a highly dynamic compartment serving as a continuum from roots through the stem to leaves and is potentially important as a bridge that perceives and transduces signals from the environment to the symplast.

Proteins secreted into apoplast might contribute to biotic and abiotic stress response as a first line of defense. A variety of these proteins have been identified in apoplast of several plants [8-20]. Such proteins predominantly represent functional categories associated with cell wall metabolism, defense, and programmed cell death. However, these studies have focused on annual plants that are not native to riverine ecosystems and have been conducted under controlled environments.

A few apoplast studies in perennial plants at the molecular level include xylem sap proteome from apple, peach, pear, poplar, as well as identification of the leaf apoplast antioxidative system in response to pox virus in plum [21-24]. Although these studies provide a basic understanding of protein composition in the apoplast of mainly horticultural species, they are limited in scope of the study, genomic resources (e.g., lack of whole genome sequence), protein source of tissues, developmental stages of trees (juvenile only), environmental conditions (mainly artificial controlled environments), and techniques. Consequently, there is a lack of a systems level understanding of the apoplast proteome and its function in riverine plant species. Thus, our goal was to elucidate a comprehensive and systems level apoplast proteome in riverine $P$. deltoides under normal conditions in addition to identifying apoplast defense mechanisms poplar has developed to respond to water and pathogen stress, which are among the most important stress factors in riverine ecosystems.

\section{Results and Discussion}

\section{Extracting protein-containing poplar apoplast fluid}

Obtaining a population of representative apoplast proteins from various tissues in poplar without symplastic contamination is technically challenging. We used a pressure-chamber method for leaves and a water-displacement method for stems to extract protein-containing apoplast fluid. To evaluate whether leaf apoplast extracts were contaminated with symplastic contents, we performed the following analyses as credible indicators of contamination. First, thin sections from pressurized and control leaves were examined using a light microscope. No ruptured cells were observed in the vicinity of stomata and within the vasculature (Figure 1A). Second, the 2-D PAGE protein profiles from leaf apoplast and whole leaf tissue were compared, and no similarity was observed in their protein patterns (Figure 1B). For example, the large subunit of ribulose-bisphosphate carboxylase (rbcL), which is symplast specific [25], was abundant in whole leaf tissues, whereas it was undetectable in the apoplast. Third, an immuno blot analysis was conducted for both symplast and apoplast protein samples. Using antibodies against the symplast proteins rbcL and malate dehydrogenase [25-27], both proteins were detected in whole-leaf tissue extracts, but not in apoplast proteome (Figure 1C). Finally, concentrations of macro and micro nutrients were significantly $(p<$ 0.001 ) lower in leaf apoplast than in whole leaf extract (Figures 1D and 1E), which is consistent with previous findings [28]. We would have expected to observe similar amounts of nutrients in symplast and apoplast if the cell membrane had ruptured due to applied pressure. We can conclude from these observations that the extracted apoplast proteins from poplar leaves were devoid of symplastic contamination, confirming previous observations that pressurization of cotton (Gossypium hirsutum) and cocklebur (Xanthium strumarium) leaves for apoplast fluid extraction did not result in symplast contamination [28-30]. We did not verify whether water-pressure of stems to obtain apoplast proteins caused contamination of the apoplast content from symplast, because the applied water pressure by gravity was considerably less than the pressure applied to leaves via pressure chamber.

\section{Systems level protein composition of poplar apoplast}

To capture the most representative apoplast proteins in a growing season, we characterized the leaf and stem apoplast proteomes under normal conditions during a period (April-June) in which trees experienced active growth, transition, cessation of primary growth, and variation in temperature, precipitation, day length, and pathogen infestation (Figure 2A and 2B). Some of these factors are related and likely synergistic in a natural environment. Using both gel-based (2-D PAGE) and gel-free (2-D LC MS/MS) proteomic approaches, we identified 144 unique proteins in leaf apoplast (Figure $2 \mathrm{C}$ ) and 135 unique proteins in stem apoplast (Figure $2 \mathrm{D}$ ), totaling at 247 proteins (Figure 2E). A previously published poplar root apoplast data (gel-based only) contained 97 proteins [22], thus totaling the number of unique proteins in the root-stem-leaf apoplast continuum at 303 (Figure 2F). Leaf apoplast proteins were mainly associated with cell wall metabolism (most abundant), stress/defense, and proteolysis (Figure 2G and additional files 1, 2 and 3: Figure S1A, and Tables S1 and S2), whereas stem apoplast proteins were mainly associated with stress/defense (most abundant), cell wall metabolism, and carbohydrate metabolism (Figure $2 \mathrm{H}$ and additional files 1, 4, and 5: Figure S1B, and Tables S3 and S4). One major difference between the two proteomes was that a substantial portion of stem apoplast 


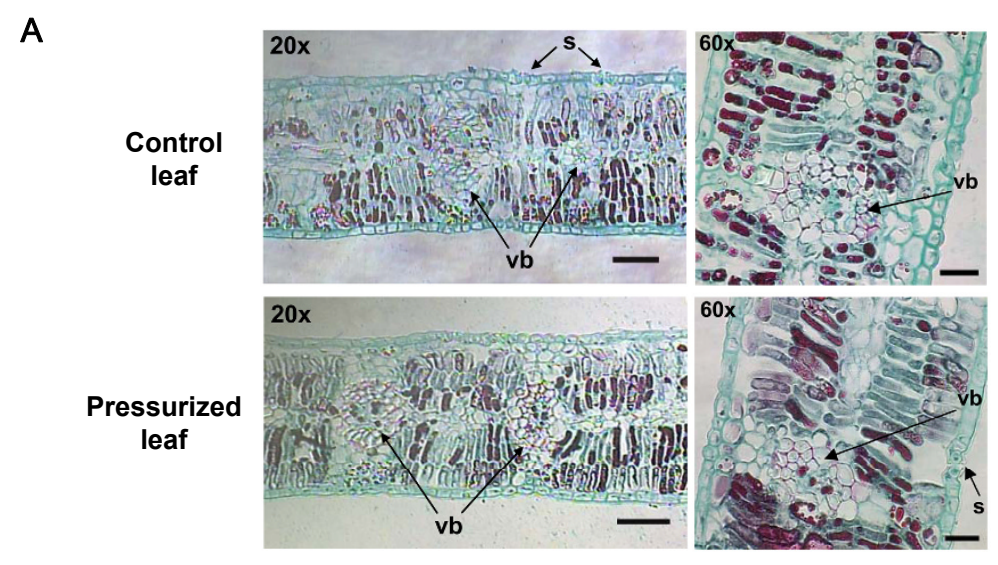

B
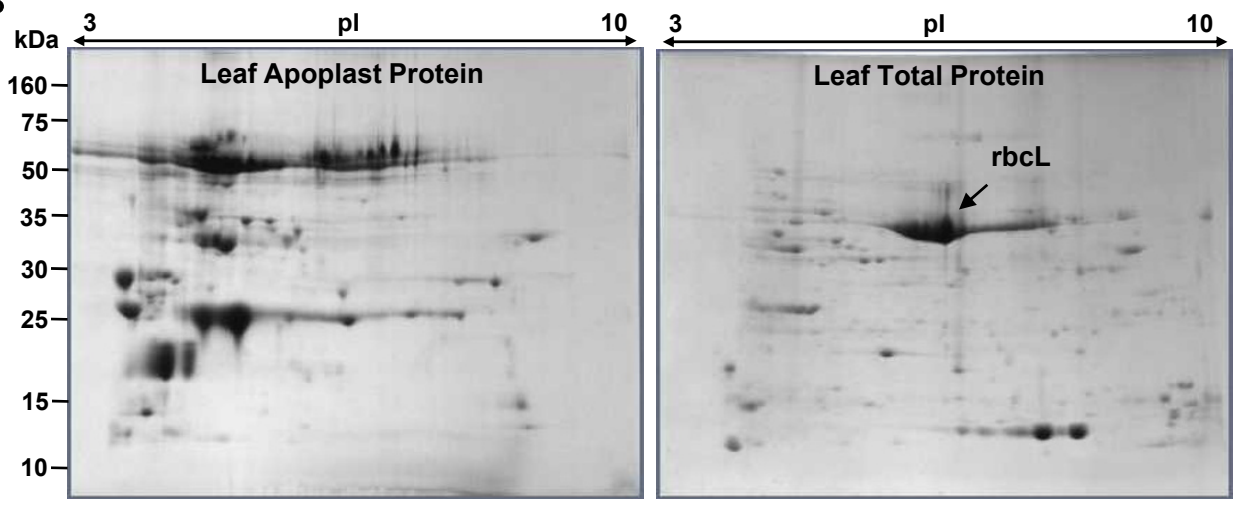

C

SDS PAGE
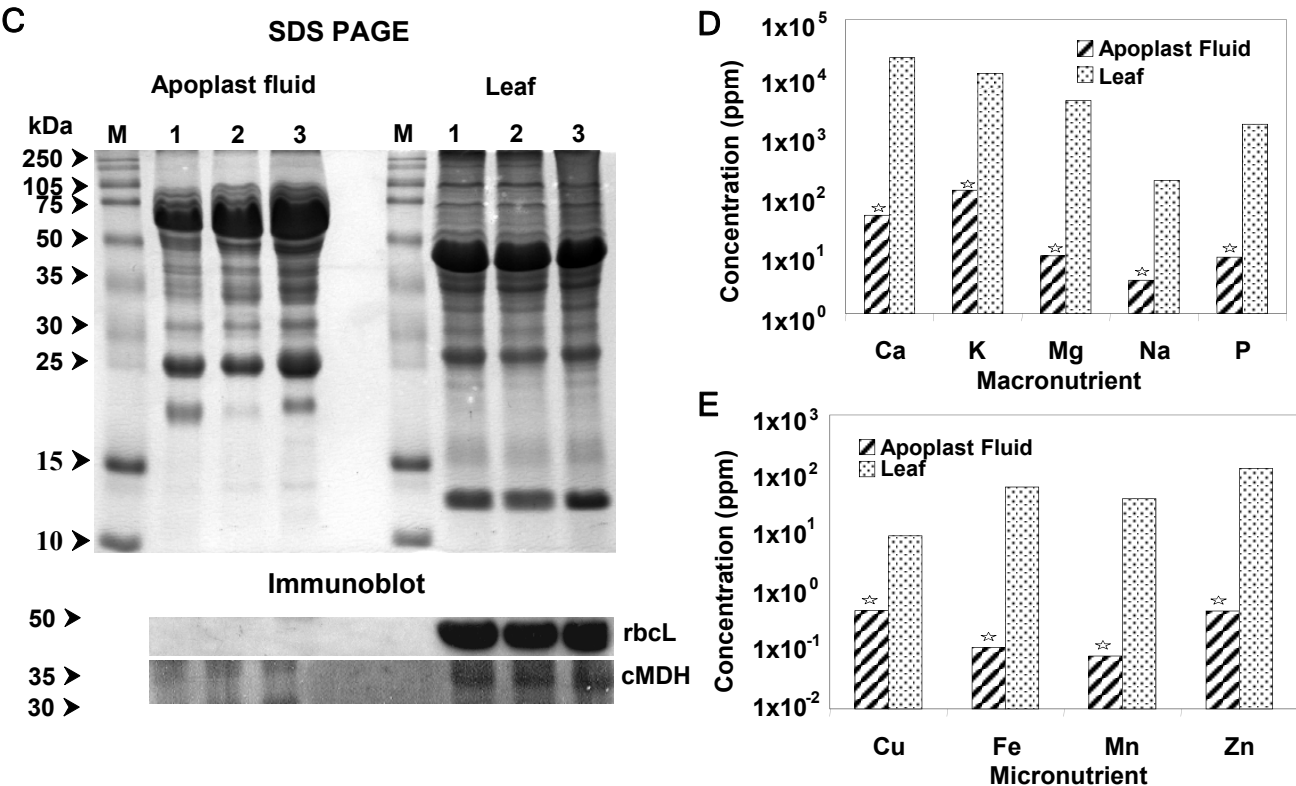

Figure 1 Assessment of symplastic contamination of leaf apoplastic extracts. (A) Light microscopy images from pressured and control $P$. deltoides leaves. S, stomata; vb, vascular bundle. Bar $=25 \mu \mathrm{m}$. (B) Protein distribution on 2-D PAGE from the extracts of leaf apoplast and whole leaf tissue. rbcL, the ribulose-1, 5-bisphosphate carboxylase/oxygenase large subunit. (C) Protein distribution on 1-D SDS PAGE and immunoblot analysis of symplastic rbcL and cytosolic malate dehydrogenase $(\mathrm{cMDH})$ using the extracts from apoplast and whole leaf tissue. $\mathrm{kDa}$, protein molecular weights. (D) Macro and (E) micro nutrients in leaf apoplast and whole leaf extracts. Asterisks indicate statistically significant $(p<0.001)$ difference in nutrients between apoplast and whole leaf extracts. Ppm, parts per million. 


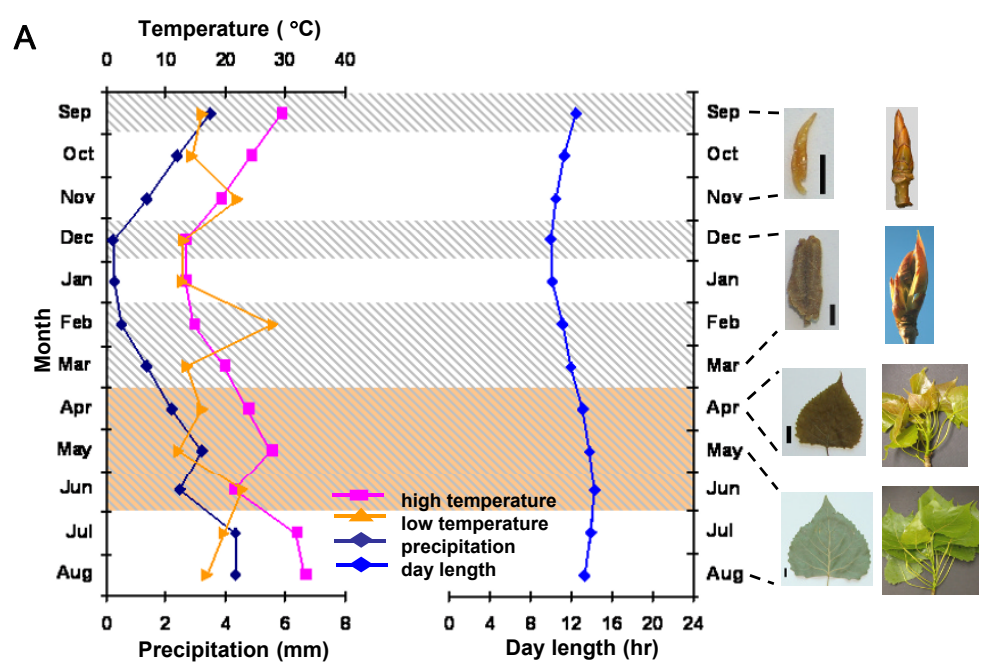

B
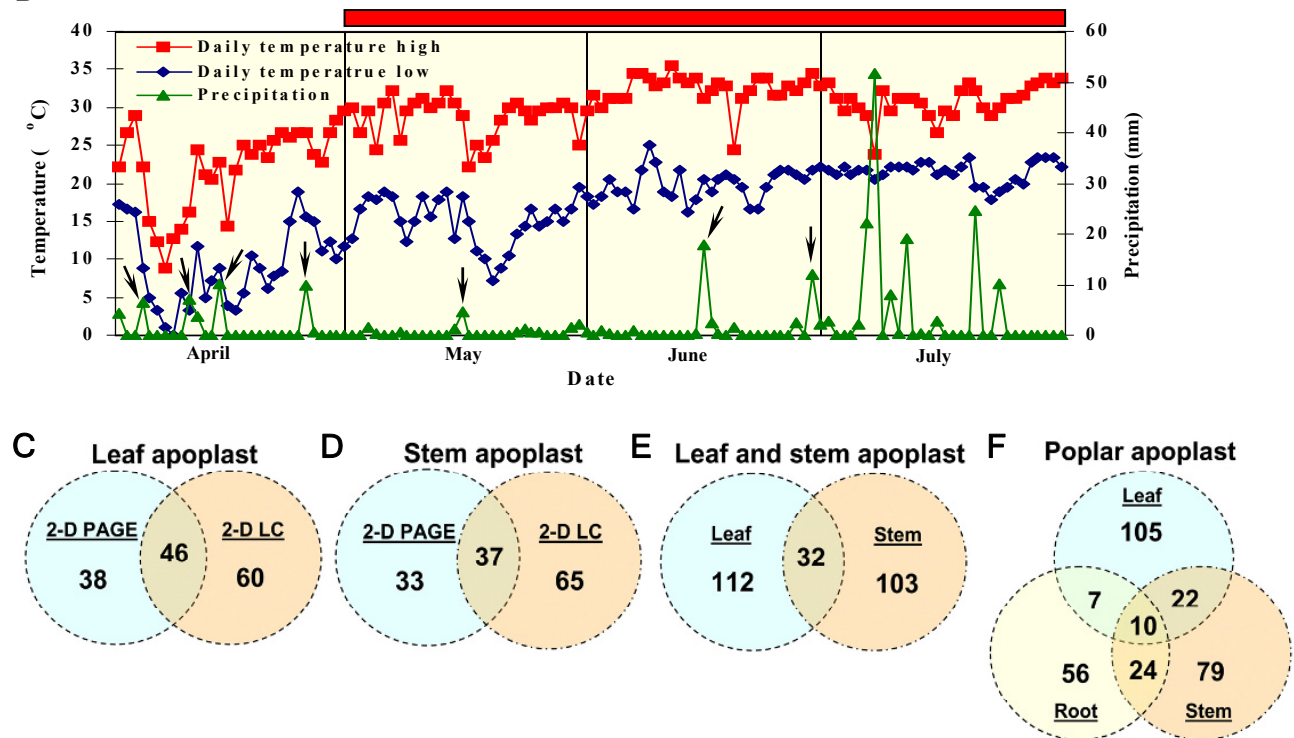

G

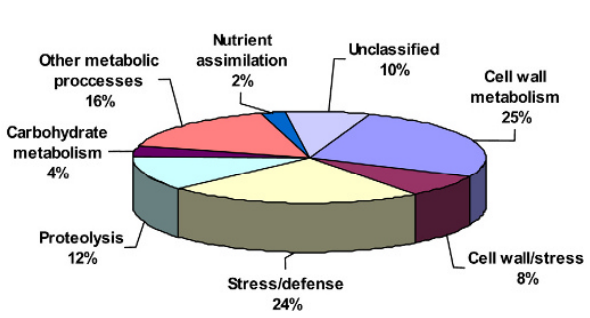

$\mathrm{H}$

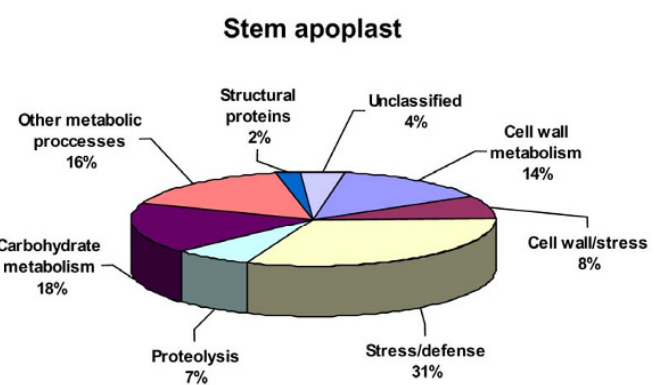

Figure 2 Environmental conditions of the field where $P$. deltoides trees were located and quantitative distribution and functional classification of apoplast proteome. (A) Average monthly high and low temperatures, precipitation, and day-length from 2003 to 2007.

Orange-color shows the sampling time of tissues for apoplast proteome, whereas the shaded background indicates the sampling of leaf tissues for transcript analysis using microarrays. Developmental stages of leaves and shoots are shown on the right during sampling. Bar $=2 \mathrm{~mm}$ (September-March) and $=1 \mathrm{~cm}$ (April-August). (B) High/low temperatures and precipitation during sampling for apoplast proteome analysis (April-July, 2007). Arrows indicate flooding times. The red bar shows normal Melampsora infestation. (C-E) Quantitative distribution of leaf and stem apoplast proteins. 84 proteins (38+46) were detected with 2-D PAGE, whereas 106 proteins $(60+46)$ were detected with 2-D LC. Both 2-D PAGE and 2-D LC detected 46 proteins. (F) Quantitative distribution of leaf, stem, and root apoplast proteins. 2-D PAGE-based poplar root apoplast proteome was from Dafoe and Constabel [22]. Functional classification of leaf $(\mathrm{G})$ and stem $(\mathrm{H})$ apoplast proteins. 
proteome (18\%), but a small portion (4\%) of leaf apoplast, was associated with metabolism of carbohydrates.

The SignalP [31] and SecretomeP [32] algorithms predicted that a substantial number of apoplast proteins (62\% root, $57 \%$ stem, and $80 \%$ leaf) follow a secretory pathway (Additional files 2, 3, 4 and 5: Tables S1-S4; [22]), suggesting that they are secreted to the apoplast. Staining with a specific glyco-dye revealed that 25 proteins (30\% of gel-based proteins) in leaf apoplast were glycosylated (Additional files 2 and 6: Table S1 and Figure S2A), which perhaps improves protein solubility, enhances thermal stability in hot summers (Figure 2B), provides protection from proteolysis, and modulates protein-protein interactions in apoplast [33-36]. Staining the gels with specific phospho-dye ProQ Diamond indicated that cysteine-rich repeat secretory protein 38 (POPTR_1698s00200.1) and thaumatin-like protein (POPTR_0018s10490.1) in leaf apoplast were potentially phosphorylated (Additional file 6: Figure S2B). This was supported with NetPhos 2.0 [37] predictions that there were six phosphorylation sites on thaumatin-like protein and 12 sites on cysteine-rich repeat secretory protein 38 . These results indicate that the leaf-stem-root apoplast continuum in poplar contains diverse proteins that appear to be post-translationally modified and involved in important functions such as cell wall metabolism, stress/defense, and carbohydrate metabolism.

\section{Apoplast-controlled response to water stress}

Poplar often experiences flooding and drought stress in riverine ecosystems $[1,3,4]$, and our experimental trees went through flooding and drought cycles (Figure 2B). To determine whether apoplast is involved in mediating water stress (flooding/hypoxia or drought) in poplar, we identified signature proteins associated with flooding and drought. Our leaf and previously published root [22] data contained alcohol dehydrogenases in addition to a number of important glycolytic enzymes in stem and root apoplasts (Figure 3). This indicates anaerobic respiration, and therefore some reliance of poplar on glycolysis and ethanolic fermentation for energy production.

Although poplar is subject to frequent oxygen deficits (hypoxia) annually due to flooding and sedimentation, they show tolerance with minimal effect on growth and survival $[1,3,5,38,39]$. To maintain energy generation under flooding, trees switch mitochondrial respiration to alcoholic fermentation in roots and stems, resulting in significantly increased ethanol biosynthesis [38,40,41]. Unlike flood-intolerant tree species, ethanol does not accumulate in roots of flood-tolerant tree species (e.g., poplar) due to effective transport from roots in the apoplast to leaves where it is efficiently converted to acetyl-CoA via alcohol dehydrogenase and used in leaf metabolism [38,40,42-46].
Consistent with these previous studies, transcripts of alcohol dehydrogenase were abundant year-round in poplar leaves (Figure 4, additional files 7, 8 and 9: Figures S3 and S4B, and Table S5, black module). In contrast, alcohol dehydrogenase gene was induced upon flooding along with the activation of its protein in poplar roots [38,43]. Poplar leaves and roots contained different alcohol dehydrogenases (Figure 3), which phylogenetically fall into different clades (Additional file 10: Figure S5): POPTR_0005s06140.1 and POPTR_0002s07290.1 in leaf apoplast, POPTR_0008s16150.1 in root apoplast, and POPTR_0002s07290.1 in root transcriptome upon flooding. Thus, we hypothesize that poplar has evolved alcohol dehydrogenases optimized for ethanol biosynthesis in roots and for ethanol catabolism in leaves.

Sucrose and starch constitute the main carbohydrate reserves in poplar roots and stems [47], and a steady supply of carbohydrates from these reserves and leaves to hypoxic roots in poplar maintains alcoholic fermentation [38]. Carbohydrates appear to be effectively cycled within the leaf-stem-root continuum via symplast and apoplast in flood-tolerant tree species to meet the carbon demands of tissues $[38,41,48]$. Sucrose synthase (POPTR_0018s07380.1), an important regulator of sink strength in poplar [49], is present in stem apoplast (Figure 3 and 5, and additional files 2, 3, 4, 5 and 11: Tables S1-S4 and S6), indicating sucrose hydrolysis and a potential channeling into the glycolysis/fermentation pathway. Invertase, which is involved in the primary mechanism of aerobic sucrose hydrolysis, is suppressed under flooding, while sucrose synthase is upregulated to catabolize sucrose in poplar [38]. Supporting this view, a constitutively expressed alpha-amylase is present in leaf apoplast (Figure 3 and 4A, and additional file 9: Table $\mathrm{S} 5$, blue module) and is perhaps involved in starch hydrolysis after mobilization of carbohydrate storage reserves. During flooding, flood-tolerant tree species maintain low starch levels in leaves, but high starch levels in roots $[42,50]$. Increased sucrose synthase expression via overexpression in poplar was associated with maintaining height growth and biomass accumulation, as well as elevated levels of cellulose synthesis (Figure 5 and additional file 11: Table S6) and deposition in the xylem secondary cell wall, resulting in thick cell walls and improved wood density [49]. Indeed, sucrose synthase was among the highly expressed genes in poplar tension wood which is cellulose enriched, suggesting sucrose synthase involvement in stress response [51]. Anoxic rice plants [52] and hypoxic wheat roots [53] showed a high level of sucrose synthase activity and abundant cellulose deposition in the secondary cell walls of wheat, which was postulated to be important for increasing mechanical stability of roots under hypoxia. When the amount of sucrose synthase was reduced in 


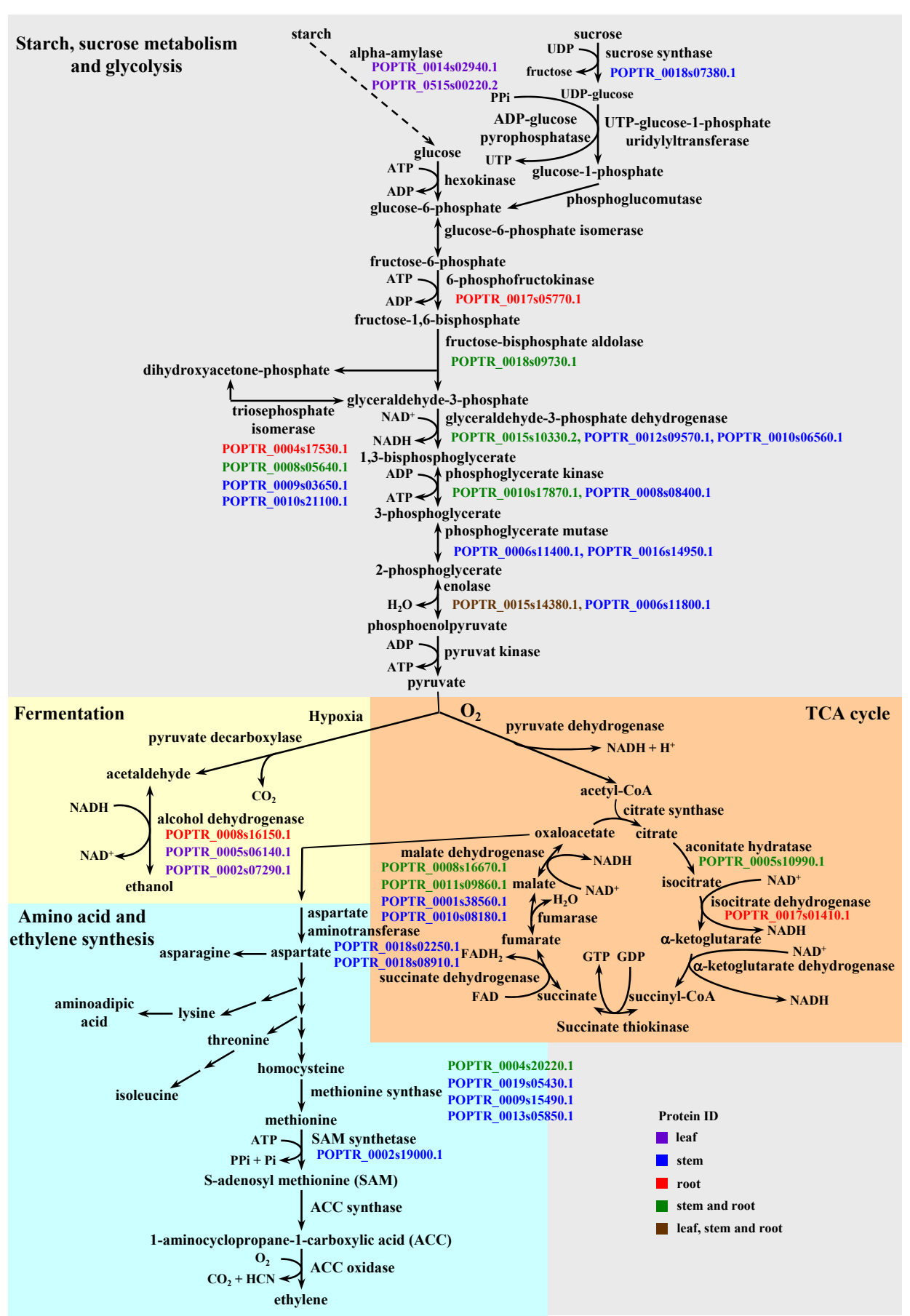

Figure 3 Carbohydrate (starch and sucrose) catabolism via glycolysis, the TCA cycle, and fermentation. Poplar leaf, stem, and root apoplast protein IDs are shown in colored numbers. The metabolic pathways were modified from Srivastava [138], Kreuzwieser et al [38], Magneschi and Perata [139], and Narsai et al [140].

roots of transgenic potatoes, roots were rapidly damaged by hypoxia and showed slow recovery when plants were returned to aerobic conditions [54]. Submerged leaves in flood water of tropical tree species that formed thick outer epidermal walls and a thick cuticle did not rot or detach from the plant during submergence [2], suggesting an improved capacity of those leaves to withstand the impact of flooding. Expression of sucrose synthase was induced by abscisic acid (ABA; Figure 5; additional file 11: Table S6; $[55,56])$, and abundant ABA was 
A
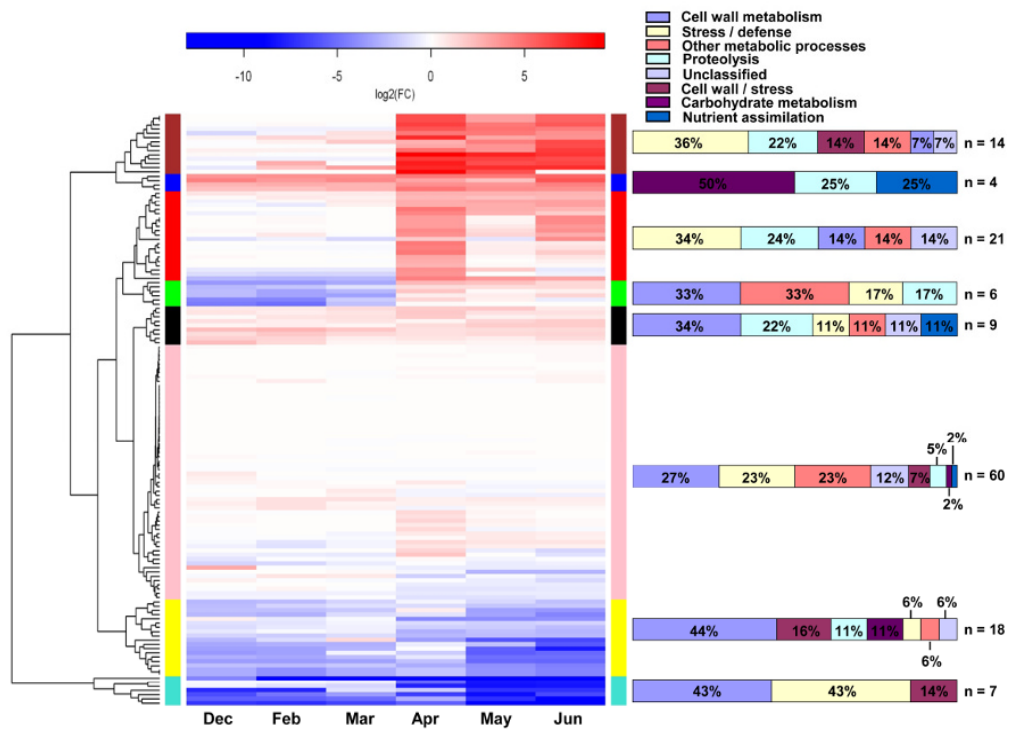

B

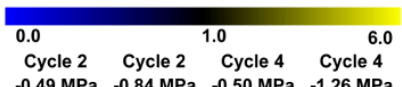
$0.49 \mathrm{MPa}-0.84 \mathrm{MPa}-0.50 \mathrm{MPa}-1.26 \mathrm{MPa}$

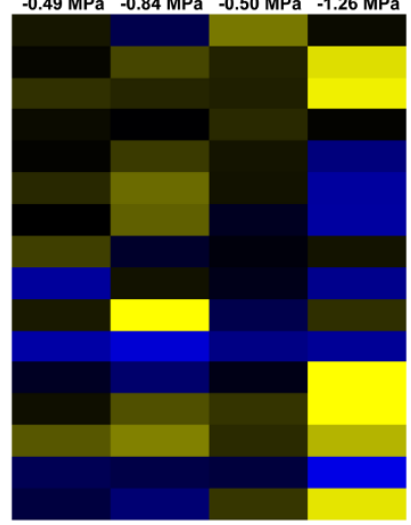

Protein description (Poplar protein I.D.)

Phenylcoumaran benzylic ether reductase (POPTR_0002s03580.1)

Isoflavone reductase related protein (POPTR_0009s12090.1)

Alcohol dehydrogenase 2 (POPTR_0002s07290.1)

Alcohol dehydrogenase (POPTR_0005s06140.1)

(-)-Isopiperitenol dehydrogenase (POPTR_0015s07660.1)

Wound-responsive (POPTR_0010s16050.1)

Populus $x$ generosa pop3 peptide (POPTR_0010s16030.1)

Unknown protein (POPTR_0001s05560.1)

Cysteine-rich repeat secretory protein 38 (POPTR 1698s00200.1)

Dehydration stress-induced protein (POPTR_0007s05650.1)

Thaumatin-like protein (POPTR_0018s10480.1)

Pathogenesis-related protein 8 (POPTR_0012s01160.1)

Acidic class III chitinase (POPTR_0015s05990.1)

Class IV chitinase (POPTR_0013s12870.1)

NtPRp27 (POPTR_0001s30680.1)

Cationic peroxidase 1 (POPTR_0016s14030.1)

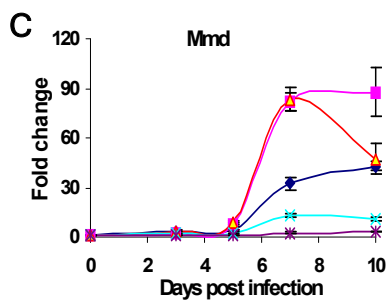

$D_{60}$

Mp

$\mathrm{E}_{4}$

OrI
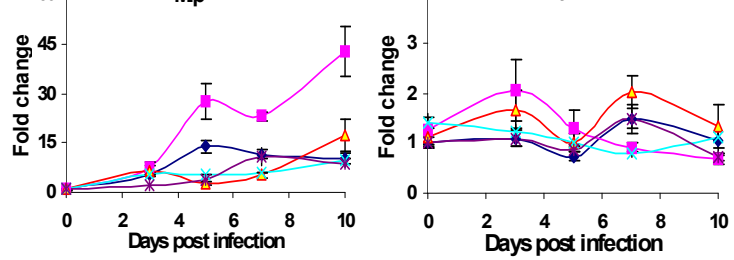

* Cysteine-rich repeat secretory protein 38 precursor (POPTR_1698s00200.1)

- Acidic class III chitinase (POPTR_0015s05990.1)

$\triangle-$ Thaumatin-like protein (POPTR_0018s10480.1)

* Cationic peroxidase 1 precursor (POPTR_0016s14030.1)

$\checkmark$ - Blight-associated p12 (POPTR_0006s19310.1)

Figure 4 Transcript levels of poplar leaf apoplast proteins and their transcriptional regulation by stress. (A) Year-round transcript levels of $P$. deltoides leaf apoplast proteins using poplar microarrays, and hierarchical clustering of the transcripts corresponding to 139 proteins. Transcript abundance over time is represented as the log2 fold-change of each time point to the baseline time point (September). Vertical bars with a color represent a module. Functional classification of each module is shown on the right with the number ( $n$ ) of genes. (B) Heat map showing response of genes corresponding to apoplast proteins at the transcript level to water stress in $P$. deltoides that was subjected to moderate $(-0.49 \mathrm{MPa})$ to severe $(-1.26 \mathrm{MPa})$ cyclical water stress. Expression less than 1.0 is down-regulated compared to control, whereas expression greater than 1.0 is up-regulated. (C-E) Transcript response of genes corresponding to apoplast proteins in leaves when poplar NM6 ( $P$. nigra X P. maximowiczii) was challenged with the isolates of M. medusae f. sp. deltoidae (Mmd) and M. laricipopulina (Mlp). Control (ctrl) tissues were also analyzed. Error bars show standard deviation about the mean. 


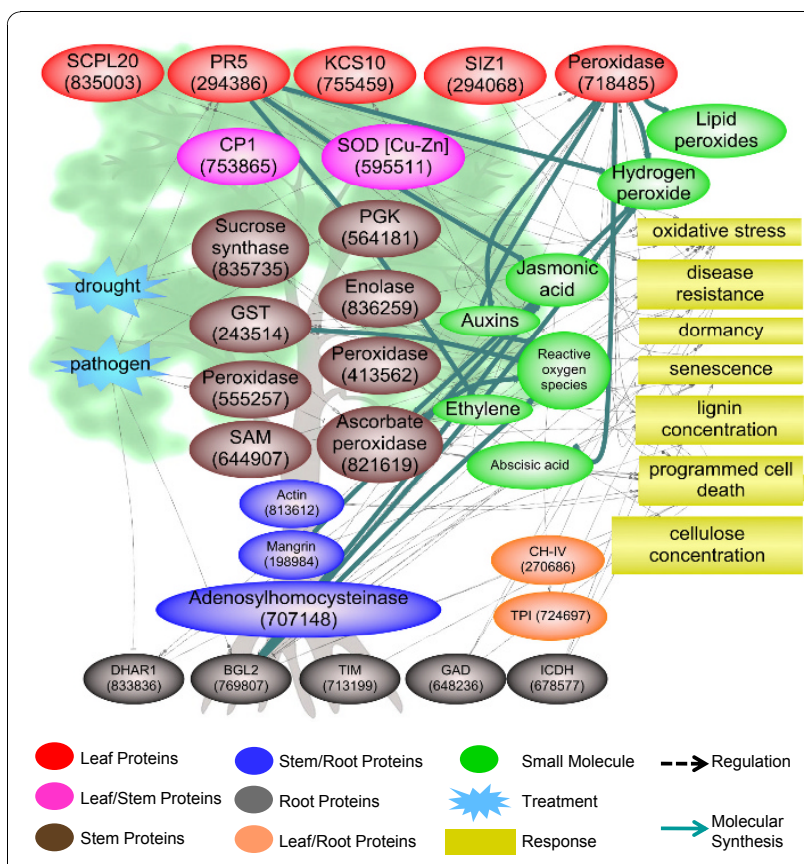

Figure 5 Modeling leaf, shoot, and root apoplast proteomics data into regulatory networks and pathways. The pathways include stress factors (drought and pathogen) upstream of proteins and physiological responses (yellow). Proteins are displayed on the background tree relative to the tissue in which they were found, except for two proteins (orange) that were found both in roots and leaves. Proteins displayed in pathways are identified by protein functional name/abbreviation followed by former poplar protein ID in parenthesis. Abbreviations in parenthesis: SCPL20 = serine carboxypeptidase-like 20, PR5 = pathogenesis-related gene 5, KCS10 = 3-ketoacyl-CoA synthase 10, SIZ1 = E3 SUMO-protein ligase, CP1 = cysteine-type peptidase, $\mathrm{SOD}=$ superoxide dismutase, $\mathrm{PGK}=$ phosphoglycerate kinase, GST = glutathione S-transferase, SAM = Sadenosylmethionine synthetase, $\mathrm{CH}-\mathrm{IV}=$ class IV chitinase, $\mathrm{TPI}=$ triose-phosphate isomerase, DHAR = dehydroascorbate reductase, $\mathrm{BGL2}$ = beta-1,3-glucanase 2, TIM = triosephosphate isomerase, GAD = glutamate decarboxylase, and ICDH = isocitrate dehydrogenase.

present in poplar leaves in the early growing season (Additional file 8: Figure S4B). However, a strong relationship between flooding and ABA signaling has yet to be established. Since flooding exerts stress, carbohydrates are also likely channeled via sucrose synthase to cellulose biosynthesis and its deposition into xylem secondary cell walls of poplar roots and stems for reinforcement.

\section{Response to drought stress}

As poplar displays an overall sensitivity to drought, it has evolved ways to cope with intensities and frequencies of water limitation in riverine ecosystems during summers $[3,4]$. To determine whether transcripts of stress-related apoplast proteins respond to water stress (drought), we applied moderate $(-0.49 \mathrm{MPa})$ to severe $(-1.26 \mathrm{MPa})$ cyclical water stress to $P$. deltoides in a controlled environment. Transcripts of apoplast proteins such as pathogenesis-related protein 8 (POPTR 0012s01160.1), acidic class III chitinase (POPTR_0 015s05990.1), cationic peroxidase 1 (POPTR_0016s 14030.1), isoflavone reductase-related protein (POPTR 0009s12090.1), and class IV chitinase (POPTR_0013s 12870.1) accumulated in leaves of poplar upon water stress (Figure 4B and additional file 12: Table S7). Our year-round transcript analysis showed that genes encoding for pathogenesis-related protein 8 (red module), acidic class III chitinase (brown module), and cationic peroxidase 1 (brown module) were activated during the growing season (Figure 4A and additional files 7, 8 and 9: Figures S3 and $\mathrm{S} 4 \mathrm{C}$, and Table S5) when trees normally experienced drought (Figure 2A and 2B). These proteins are stress/defense related and appear to be secreted (Additional files 2, 3, 4 and 5: Tables S1-S4), perhaps suggesting their role in poplar apoplast to decrease the risk of pathogen and insect infestation under drought.

Our poplar apoplast data (Figure 5 and additional files 2, 3, 4, 5 and 11: Tables S1-S4 and S6) contained ascorbate peroxidase 1 (POPTR_0009s02070.1), methionine synthase (POPTR_0009s15490.1), mangrin/allene oxide cyclase (POPTR_0004s10240.1), heat shock protein 70-3 (POPTR_0010s21280.1), DnaK-type molecular chaperone hsp70 (POPTR_0008s05410.1), blight associated p12 (POPTR_0018s10730.1), and $\mathrm{Cu}-\mathrm{Zn}$ superoxide dismutase (POPTR_0005s04590.1) that are responsive to drought (Additional file 12: Table S7). These proteins fall into the stress/defense functional category, except for methionine synthase which is involved in other metabolic processes. Heat shock proteins are considered as molecular chaperons involved in various processes including refolding of damaged proteins and protection against denaturation under drought [57]. The presence of methionine synthase and SAM synthase (Figure 3) indicates ethylene biosynthesis in poplar stem apoplast. Mangrin/allene oxide cyclase is involved in jasmonate biosynthesis [58], and existence of this enzyme in poplar root apoplast indicates the biosynthesis of jasmonate. Ethylene and jasmonate are widely involved in signaling biotic and abiotic stress (Figure 5 and additional file 11: Table S6). Ethylene likely plays a role in poplar shoot senescence (sacrifice of some of the current year's shoots) during hot and dry periods of low stream flow in summer that we often observed in our experimental $P$. deltoides trees. Shoot senescence is a common phenomenon in poplar [4] and perhaps reduces transpirational demand enabling the remaining shoots to maintain a favorable water balance.

\section{Apoplast-mediated response to biotic stress}

Poplar has to cope with biotic stress, particularly the prevalent leaf fungal rust Melampsora in riverine 
ecosystems. Melampsora infects leaves via the apoplast [59]. To explore whether transcripts of stress-related apoplast proteins respond to pathogen challenges, we infected the poplar clone NM6 ( $P$. nigra x $P$. maximowiczii) with Melampsora medusae f. sp. deltoidae $(M m d)$ and Melampsora larici-populina (Mlp). Mmd infection caused partial pathogen growth with macroscopic leaf necroses, whereas $M l p$ infection resulted in the formation of many uredinias on the leaf epidermis [60], suggesting that NM6 is more resistant to $\mathrm{Mmd}$. Each transcript showed a distinctive profile over time after the infection (Figure 4C-E). The amplitude of gene expression was much higher following the $M m d$ infection, indicating an active defense response resulting in reduced fungal growth. Conversely, relatively weak or delayed gene expression occurred following the infection with $M l p$. The difference perhaps reflects the variation in pathogenicity and host.

Transcripts of leaf apoplast proteins such as acidic class III chitinase, thaumatin-like protein, blight-associated protein $\mathrm{p} 12$, cationic peroxidase 1 , and cysteinerich repeat secretory protein 38 accumulated following Melampsora infection (Figure 4C-E). While the poplar leaf apoplast contained three different acidic class III chitinases (POPTR_0015s05990.1, POPTR_0014s08860.1, POPTR_0015s06000.1), only a single chitinase (POPTR_ 0015s05990.1) was detected in stem apoplast (Additional files 2, 3, 4 and 5: Tables S1-S4). Three different class IV chitinases (POPTR_0019s12360.1, POPTR_0013s 12870.1, and POPTR_0019s12350.1) were also detected only in poplar leaf apoplast (Additional files 2, 3, 4 and 5: Tables S1-S4). Transcripts of acidic class III chitinase (POPTR_0015s05990.1) increased in abundance when poplar ( $P$. trichocarpa x $P$. deltoides 'Beaupre') was challenged with $M$. larici-populina (Additional file 12: Table S7). Moreover, transcripts encoding acidic class III chitinase (POPTR_0015s05990.1) and PR-8 (POPTR_0012s01160.1) rapidly increased in abundance when water stress (drought) was applied (Figure 4B and additional file 12: Table S7), suggesting a broader role of these proteins in stress response.

Chitinases and $\beta$-1,3-glucanases (POPTR 0016s05800.1, POPTR_0001s26210.1, POPTR_0006s04670.1, POPTR_0 $001 \mathrm{~s} 26210.1$ ) were found together in poplar leaf and stem apoplast (Additional files 2, 3, 4 and 5: Tables S1-S4) and other plant species $[11,14,15,17,21,24]$. Chitinases are often co-induced with antifungal $\beta$-glucanases (PR-2 proteins), acting synergistically to limit fungal growth via degrading chitin and glucan of fungal cell walls [61-64]. These PR proteins likely mediate defense responses via activation of a signaling pathway through released elicitors from fungal cell walls into apoplast [65-68]. Furthermore, chitinases and $\beta$-glucanases appear to act synergistically with thaumatin-like proteins that can bind to $\beta-1,3-$ glucans for hydrolysis $[69,70]$. The poplar thaumatin-like protein (POPTR_0018s10490.1) was present in two abundant isoforms in only leaf apoplast (spots 87 and 88; additional files 1 and 2: Figure S1A and Table S1). Genes of these thaumatin-like proteins were activated in response to infection of poplar leaves with $M l p$ (Additional file 12: Table S7). While transcripts of blight-associated protein p12 (POPTR_0006s19310.1) were activated by Melampsora infection (Figure 4C-E and additional file 12: Table S7), another poplar apoplast blight-associated protein $\mathrm{p} 12$ (POPTR_0018s10730.1) was upregulated by drought (Additional file 12: Table S7), suggesting that both family members are involved in stress response. Transcripts of these poplar apoplast proteins along with pathogenesisrelated protein 8 (POPTR_0012s01160.1), hevamine (POPTR_0015s05980.1, a chitinase; [71]), and NtPRp27 (POPTR_0001s30680.1, POPTR_0009s09750.1) were abundant during the growing season and showed similar expression patterns (Figure 4A, additional files 7, 8 and 9: Figures S3, S4 D and S4E, and Table S5, red, brown, or green module), indicating co-regulation by water stress and pathogens. Some of these proteins and their homologs (e.g., chitinase and $\beta$-glucanase) in plants were regulated by ethylene (Figure 5 and additional file 11: Table S6; $[13,67,72,73])$ whose biosynthesis likely occurs in poplar apoplast (Figure 3). Thus, we postulate that poplar has developed an apoplast defense mechanism against pathogens by activating pathogenesis-related proteins under abiotic stress in riverine ecosystems.

\section{Cell wall modification in apoplast}

As plant cell walls are modified in response to stress [74], we determined the extent to which apoplast proteins are involved in stress-induced cell wall modification in poplar. Eighteen different peroxidases (POX) were detected in poplar root, stem, and leaf apoplast, and virtually all of them were predicted to be extracellular (Additional files 1, 2, 3, 4, 5, and 13: Figure S1, Tables S1-S4, and Figure S6; [22]), indicating an abundant and diverse presence of peroxidases in the poplar apoplast. The poplar leaf apoplast POX gene (POPTR_0016s14030.1) was up-regulated in response to water stress (Figure 4B) and Melampsora infection (Figure 4C-E), implying a broader role in defense. The poplar leaf apoplast peroxidases (POPTR_0016s 14030.1, POPTR_0014s14000.1) closely clustered (Additional file 13: Figure S6) with defense-related peroxidases POX8.1, POX22.3, POC1, pod2, pod4, PO2, POD1, and swpb4 [75-79]. Cationic peroxidase POC1 accumulated in the apoplast and cell walls of xylem vessels where it was involved in pathogen-induced lignification [80-82]. Lignin deposition in leaf cell walls was observed at infected sites following the interaction between Melampsora and poplar [59]. Moreover, 
transcripts of POPTR_0016s14030.1 and POPTR 0014s14000.1 showed a similar expression pattern and were only abundant during the growing season in poplar leaves (Figure 4A, additional files 7, 8 and 9: Figures S3 and S4C, and Table S5, brown module). These two peroxidases are likely involved in stressinduced lignification during the growing season in poplar leaf apoplast. Their role in defense may include reinforcement of cell walls to restrict pathogen invasion via oxidative cross-linking of monolignols, polysaccharides, and proteins such as proline-rich glycoprotein present in the poplar apoplast (POPTR 0006s18230.1; additional file 2: Table S1).

The majority of the stem apoplast peroxidases (POPTR_0005s14190.1, POPTR_0003s21640.1, POPTR 0003s21620.1, POPTR_0003s21610.1, POPTR_0001s 05050.1, POPTR_0001s04850.1, and POPTR_0003s $21660.1)$ that are all anionic $(\mathrm{pI}<7)$ clustered together in the phylogenetic tree (Additional file 13: Figure S6). Some of these peroxidases in the same cluster were also detected in leaves (POPTR_0005s14190.1, POPTR 0001s05050.1, and POPTR_0003s21660.1) along with two leaf-specific (POPTR_0007s05100.1 and POPTR_ 0016s05860.1) or root-specific proteins (POPTR_0005s 14190.1 and POPTR_0003s21660.1). Transcripts of four peroxidases (POPTR_0003s21660.1, POPTR_0149s 00200.1, POPTR_0005s14190.1, and POPTR_0007s 05100.1) showed year-round expression (Figure 4A, additional files 7 and 9: Figure S3 and Table S5, pink and yellow modules). Melampsora infection induced transcription of one particular peroxidase (POPTR_0001s04850.1) in poplar (Additional file 12: Table S7). The related peroxidases PO3, prxA3a, and PXP3-4 in poplar have been proposed to serve as key enzymes for lignifications [59,83-91]. Other poplar peroxidases in the same cluster (PO1 and PO2) are suberization-specific [90], and wound-inducible peroxidases are involved in suberization to help tissue healing [92]. Thus, we anticipate that these apoplast peroxidases are involved in lignification and suberization in poplar stems.

Four poplar apoplast peroxidases (POPTR_0015s 00580.1, POPTR_0017s06550.2, POPTR_0007s02580.1, and POPTR_0004s14240.1) closely clustered (Additional file 13: Figure S6) with a poplar peroxidase (CWPO-C) that is proposed to play a role in lignification $[88,89]$. CWPO-C, whose transcripts are constitutively expressed in the developing leaf and shoot xylem, oxidizes sinapyl alcohol, a component of poplar lignin along with coniferyl alcohol. Transcripts of three peroxidases (POPTR_0017s06550.2, POPTR_0007s02580.1, and POPTR_0004s14240.1) were expressed during leaf development (Figure 4A, additional files 7 and 9: Figure S3 and Table S5, turquoise and yellow modules). One peroxidase (POPTR_0007s02580.1; 718485) appears to be responsive to drought and pathogens, as well as auxin and abscisic acid (Figure 5 and additional file 11: Table S6). As this particular peroxidase is an important hub, we predict that it plays an important role in mediating biotic and abiotic stress in poplar. Consequently, these four poplar apoplast peroxidases are probably involved in lignin polymerization in the apoplast of developing roots, leaves, or stems. Taken together, these observations indicate that poplar possesses a large number of peroxidases in the root-stem-leaf apoplast continuum to modify cell wall structure in response to stress.

\section{Antioxidative capacity of poplar apoplast}

Metabolic reactions, stress-induced processes, and oxygen presence are expected to produce reactive oxygen species (ROS) such as superoxides and $\mathrm{H}_{2} \mathrm{O}_{2}$ in apoplast. Actively lignifying xylem tissues, particularly in stems during the growing season, sustain $\mathrm{H}_{2} \mathrm{O}_{2}$ production for cross-linking of lignin precursors by peroxidase involvement, increasing the apoplast oxidative load [83,93-96]. ROS were also increased in response to pathogen attack, leading not only to enhanced signal circulation that activates downstream antimicrobial proteins and phenolic compounds, but also to peroxidasedependent cell-wall lignification, preventing pathogen penetration [97-101]. However, we do not have an understanding of how poplar counters oxidative stress in the apoplast.

Superoxide dismutase (POPTR_0011s01280.1, POPTR_0005s04590.1, and POPTR_0013s03160.1), ascorbate peroxidase (POPTR_0009s02070.1 and POPTR_0016s08580.1), monodehydroascorbate reductase (POPTR_0006s11570.1), and peroxiredoxin (POPTR_0019s04070.1) were present in poplar stem apoplast (Figure 5 and additional files 2, 3, 4, 5 and 11: Tables S1-S4 and S6). Two superoxide dismutases (POPTR_0011s01280.1 and POPTR_0005s04590.1) were the only antioxidant enzymes present in leaf apoplast (Additional files 2 and 3: Tables S1 and S2). Transcripts of one superoxide dismutase (POPTR_0005s04590.1) showed a year-round expression in leaves (Figure 4A, additional files 7 and 9: Figure S3 and Table S5, yellow module). These specialized antioxidant enzymes and low-molecular weight antioxidants such as ascorbate and glutathione are particularly involved in buffering oxidation [101-104]. Although none of these enzymes were detected in the poplar root apoplast [22], thioredoxin (POPTR_0005s25420.1) in the root apoplast might play a role in the regeneration of peroxiredoxin [105].

We anticipate that superoxide dismutase in poplar apoplast reduces superoxide ions into $\mathrm{H}_{2} \mathrm{O}_{2}$ which is then reduced to $\mathrm{H}_{2} \mathrm{O}$ by ascorbate peroxidase $[96,106,107]$. 
One of the superoxide dismutases (POPTR_0005s04590.1) was responsive to drought in poplar [108], while the other one (POPTR_0013s03160.1) was responsive to Melampsora (Additional file 12: Table S7). Knockdown of an extracellular high-isoelectric-point superoxide dismutase in poplar accelerated maturation, ROS accumulation, and lignification in the secondary cell walls with a number of developmental disturbances such as reduced growth, thinner stems, smaller leaves, and shorter and thinner xylem fibers and vessels [109], indicating the importance of superoxide dismutases in stress response and plant development. The presence of monodehydroascorbate reductase in the poplar apoplast indicates the regeneration of ascorbate for continuous removal of $\mathrm{H}_{2} \mathrm{O}_{2}$. Other antioxidant enzymes detected in stem apoplast include glyoxalase I (POPTR_0009s01280.1; additional file 4: Table S3) that removes methylglyoxal, a toxic by product of carbohydrate and amino acid metabolism [110,111], and glutathione Stransferase (POPTR_0483s00220.1 and POPTR_0002s 20890.1; Figure 5 and additional files 4 and 11: Tables S3 and S6) that detoxifies xenobiotic compounds [112-114]. These observations suggest poplar has a robust apoplast antioxidative system.

\section{Conclusions}

Our study shows that poplar has developed a diverse apoplast proteome in the leaf-stem-root continuum. Such a complex proteome appears to play a major role in mediating water, pathogen, and oxidative stress, suggesting that a systems level mechanism has evolved in poplar apoplast allowing encounters of multiple stresses while maintaining growth and development over many years. We anticipate our work to be a starting point for developing a systems level understanding of how the extracellular matrix mediates multistress responses in plant species of riverine ecosystems under fluctuating environmental conditions.

\section{Methods}

\section{Apoplast fluid extraction}

All sampled Populus deltoides trees were naturally growing along Sand Creek within the Tombigbee River system MS, USA ( $33^{\circ} 27^{\prime} 45^{\prime \prime} \mathrm{N}$; 88 $49^{\prime} 12^{\prime \prime} \mathrm{W}$ ), for which weather data have been regularly collected and archived by Mississippi State University http://ext.msstate.edu/ anr/drec/weather.cgi. Three sexually mature male trees $(15,25$, and 30 years old) were selected for leaf apoplast analysis. We used a bucket truck with a hydraulic extending and elevating winch to reach the upper crown of 25-m-tall trees. For stem apoplast analysis, twenty different male and female sexually immature trees with ages ranging from 3 to 6 years old were sampled. For leaves, a pressure chamber (Soilmoisture Equipment, Santa Barbara, CA) was used to extract apoplast fluid.
The instrument contained a pressure-safe vessel attached to a pressure gauge. Current-year shoots with expanding and fully-expanded leaves (Figure 2A) were sampled separately from each tree in May-June, 2007. Shoots from each tree were collected between 8:00 AM and 9:00 AM daily (except weekends) and kept on ice. This fixed sampling time took into account that apoplast proteins and their corresponding transcripts might show circadian variation as many genes do in Arabidopsis thaliana [115]. In the laboratory, individual leaves were cut at the base of petiole, and cut surfaces were rinsed with sterile water. The leaf lamina was then placed into the pressure chamber with the petiole protruding outside. Using an ultra high purity compressed nitrogen gas, pressure was slowly increased within the chamber to $300 \mathrm{psi}(2 \mathrm{MPa})$ at which apoplastic fluid started to exude. Pressure below 300 psi did not produce any extract. Exuding apoplast fluid was collected for one minute into a sterile tube that was placed on ice and contained $500 \mu \mathrm{l}$ of cold two-times concentrated protein extraction buffer $(1.8 \mathrm{M}$ sucrose, $1 \mathrm{M}$ Tris-base, $0.1 \mathrm{M} \mathrm{Na}_{2}$-EDTA, $0.2 \mathrm{M} \mathrm{KCl}, 4 \% \beta$-mercaptoethanol, $\mathrm{pH}$ 8.7). The first drop of the extract was discarded to avoid contamination from broken cells at the cut site. Each tube was filled with $500 \mu \mathrm{l}$ of apoplast fluid to make the final volume $1 \mathrm{ml}$. 100-200 $\mu \mathrm{l}$ of apoplastic fluid were extracted from each leaf. Collected extracts were immediately subjected to protein extraction. Three replications of apoplast fluid per tree were obtained in tubes for gel-based and gel-free protein analyses. Multiple tubes within a replication were pooled during protein extraction.

For stems, a water-replacement method was used to extract apoplast fluid. Stems of size 40-90 cm in length and 1-4 $\mathrm{cm}$ in diameter were collected between 8:00 and 9:00 AM in April-June, 2007 and kept on ice. In the laboratory, short sections $(2.0-2.5 \mathrm{~cm})$ of the bark at both stem ends were removed. The stem ends were then rinsed with deionized water. Plastic tubing was attached to the upper stem end over the exposed tissue and sealed with Parafilm to avoid leakage. The bark at the site of cut of the lower end of the stem was tightly wrapped with Parafilm to avoid contamination from phloem. Stems were positioned vertically, and deinonized water was applied to the tubing attached to the upper stem end. Exudate flowing from the bottom end was collected into sterile tubes placed on ice for several minutes. The first drop was discarded. Depending on the stem size, 1-5 ml of apoplast fluid mixed with water was collected from an individual stem. Apoplast fluid was filtered with sterile $0.2 \mu \mathrm{m}$ syringe filters (Fisher Scientific, Pittsburgh, PA) to remove particulate matter, pooled, and either frozen at $-80^{\circ} \mathrm{C}$ or immediately used for protein extraction. Three replications of apoplast 
fluid from all the stems were obtained in tubes. Pooled sap was concentrated on Amicon Centriplus YM-3 filters (Millipore Corporation, Bedford, MA) to 1/30 of original volume. Proteins were precipitated by adding four parts of $12.5 \%$ trichloroacetic acid and $0.1 \% \beta$-mercaptoethanol in $100 \%$ acetone [116]. Precipitation was carried out at $-80^{\circ} \mathrm{C}$ overnight. Proteins were sedimented by centrifugation at $6,000 \times g$ for $10 \mathrm{~min}$, and the pellet was washed three times with ice-cold $80 \%$ acetone and once with $100 \%$ acetone and stored at $-80^{\circ} \mathrm{C}$.

\section{Protein extraction and gel-based protein analysis}

Total proteins were extracted from apoplast fluid using a phenol-based procedure with modifications [117]. For each replication of protein extraction, apoplast fluid from five tubes was pooled, and five milliliters of Trissaturated phenol ( $\mathrm{pH} 8.0$ ) were added. After $10 \mathrm{~min}$ of shaking, homogenate was centrifuged at $6,000 \times g$ for 20 min, and the phenol phase was carefully removed. Proteins were precipitated from phenol phase using five volumes of precipitation solution $(0.1 \mathrm{M}$ ammonium acetate and $1 \% \beta$-mercaptoethanol in methanol). Precipitation was carried out overnight at $-70^{\circ} \mathrm{C}$. Precipitated proteins were collected by centrifugation at $6,000 \times g$ for $10 \mathrm{~min}$ and washed three times with cold precipitation solution and three times with cold $80 \%$ acetone. Each wash was followed by centrifugation at $6,000 \times g$ for 5 min. Following the last acetone wash, protein pellets were air-dried and stored at $-20^{\circ} \mathrm{C}$. Approximately 25-30 leaves were used to obtain $2.5 \mathrm{ml}$ of apoplast fluid, which produced 200-250 $\mu \mathrm{g}$ of protein. The same protocol was used for extracting total proteins from whole leaves, except that two additional extractions of proteins from the phenol phase were carried out in order to remove interfering substances richly present in leaf tissue.

For resolving leaf apoplast proteins, two-dimensional polyacrylamide gel electrophoresis (2-D PAGE) was employed as previously described [118]. Protein spots were visualized by staining with Coomassie Brilliant Blue G-250 (Bio-Rad, Hercules, CA). Gels were scanned with VersaDoc 3000 imager (Bio-Rad) and analyzed with PDQuest (Bio-Rad). Three replications of 2-D gels were performed per tree, totaling nine gels. The landmark semi-automatic method was used to create a match set using all nine 2-D images, and the resulting master image was used for annotation of spots. Correct matching of all spots was manually inspected. The master image included protein spots present in all three poplar trees as well as spots that were present in at least two replications of gels per tree. Reproducible protein spots were subjected to downstream proteomic analyses.

For resolving stem apoplast proteins, the leaf apoplast protein procedure was followed. However, the amount of proteins $(570 \mu \mathrm{g})$ was only sufficient for a large format 2-D gel $(14 \mathrm{~cm} \times 18 \mathrm{~cm} \times 1.5 \mathrm{~mm})$. Proteins were therefore visualized by Deep Purple Total Protein Stain (Amersham Biosciences, Piscataway, NJ). The gel was scanned using the Typhoon 9410 imager (Amersham Biosciences).

For protein spot picking, in-gel digestion, and MS/MS, we followed a previous procedure [118], except that protein identification was conducted by searching against the poplar database http://genome.jgi-psf.org/Poptr1_1/ Poptr1_1.home.html. We were unable to identify three abundant protein spots in leaf apoplast (83, 87, and 88). Thus, we had to have $\mathrm{N}$-terminal sequencing conducted by Cambridge Peptides [http://www.cambridgepeptides. com; additional file 14: Table S8]. The sequences were then searched against the poplar protein database using BLASTP, and the best matching similar protein was considered as the corresponding protein. The N-terminus sequence AGIAIYWGQNNN (spot 83) was present in two poplar proteins (POPTR_0015s05990.1 and POPTR_0012s01160.1). Thus, both proteins had to be included in our data set.

\section{Gel-free protein analysis}

Two-dimensional liquid chromatography tandem mass spectrometry (2-D LC ESI/MS/MS) was used to analyze apoplast protein mixtures from leaves and stems. Frozen protein pellets were dissolved in $50 \mu \mathrm{l}$ of $0.1 \mathrm{M}$ ammonium bicarbonate and $4 \mathrm{M}$ urea (Fraction 1 ). The remaining un-dissolved proteins were further dissolved in $50 \mu \mathrm{l}$ of $0.1 \mathrm{M}$ ammonium bicarbonate and $8 \mathrm{M}$ urea (Fraction 2). Protein concentration was determined using 2-D Quant Kit (Amersham Biosciences). Aliquots of $200 \mu \mathrm{g}$ of proteins were subjected to in-solution digestion. First, proteins were reduced by adding $1 / 10$ volume of $50 \mathrm{mM}$ dithiothreitol (DTT) and incubating for $1 \mathrm{~h}$ at room temperature. Alkylation was performed by adding $1 / 10$ volume of $100 \mathrm{mM}$ iodoacetamide and incubating for $30 \mathrm{~min}$ at $30^{\circ} \mathrm{C}$ in the dark. Before digestion, both protein samples (Fraction 1 and 2) were diluted (4X and $8 \mathrm{X}$, respectively) with $25 \mathrm{mM}$ ammonium bicarbonate to reduce urea concentration. HPLCgrade acetonitrile was added to each sample for a final concentration of 5\%. Sequencing-grade modified trypsin (Promega, Madison, WI) was then applied to a final substrate/trypsin ratio of 50:1. Digestion was carried out at $37^{\circ} \mathrm{C}$ for $12-16$ hours.

The peptide mixture was acidified with concentrated acetic acid and desalted with a peptide macro-trap according to manufacturer's instructions (Michron BioResources, Auburn, CA). Peptides were lyophilized with a SpeedVac (LABCONCO, model LYPH-LOCK 6, Kansas City, MO) and stored at $-80^{\circ} \mathrm{C}$. Immediately before mass spectrometry, the peptides were resuspended in $20 \mu \mathrm{l}$ of 
$0.1 \%$ formic acid and 5\% acetonitrile. Four replications of samples (both containing Fraction 1 and Fraction 2) were analyzed.

Following a previous procedure [119] with a slight modification, 2-D LC ESI/MS/MS was performed using ProteomeX Workstation (ThermoFinnigan, San Jose, CA) that included the Surveyor auto sampler and the Surveyor HPLC unit coupled directly in-line with LCQ Deca XP Plus - Electro Spray Ionization (ESI) ion trap mass spectrometer capable of MS/MS (in time) analysis. For the first dimension, peptides were separated on a strong cation exchange (SCX) BioBasic column (0.32 $\mathrm{mm} \times 100 \mathrm{~mm}$ ) (ThermoElectron, San Jose, CA). The following five-steps were used to elute peptides from SCX column: 0, 10, 23, 37, and $700 \mathrm{mM}$ ammonium acetate (all in $5 \%$ acetonitrile and $0.1 \%$ formic acid). For the second dimension, peptides were loaded directly onto BioBasic C18 reverse phase column (100 $\mathrm{mm} \times$ $0.18 \mathrm{~mm}$ ) equilibrated with $0.1 \%$ formic acid and $5 \%$ acetonitrile. The following acetonitrile gradient in $0.1 \%$ formic acid was applied to elute the peptides: $5-10 \%$ for $1 \mathrm{~min}, 10-30 \%$ for $19 \mathrm{~min}, 95 \%$ for $7 \mathrm{~min}, 5 \%$ for 10 min. Total elution and spectra collection time was 37 min. The mass spectrometer Data Dependent method including dynamic exclusion was designed to have four scan events: one MS scan (m/z range: 300-1700) and three MS/MS scans of three most intense ions detected in MS scan. Collected spectra were processed with BioWorks 3.1 SR1 software (ThermoFinnigan). TurboSequest was used for protein identification by matching the experimental masses of parent and fragmented ions/ peptides to those in the poplar protein database. The search parameters were that 1] peptide mass tolerance (precursor ion) was set at $1.4 \mathrm{amu}, 2]$ two internal cleavage sites were allowed for trypsin, and 3] group Scan was set at 7, minimum Group Count at 1, and minimum Ion Count at 15. Charge State and MSn level were set as Auto (peptide, 2.50; fragment ions, 0.00; ion series, $\mathrm{B}$ and $\mathrm{Y}$ ). The following modifications were considered: $C=57.05$ (differential) for carbamidomethylation of cysteins by iodoacetamide and $M=32.0$ (differential) for oxidation of methionines. All accepted peptides had to be fully tryptic, had a $\Delta \mathrm{Cn} \geq 0.08$, and had the minimum cross correlation (Xcorr) value of 1.9 ( +1 charge), 2.2 (+2 charge), and 3.75 (+3 charge). We only considered hits with at least one unique peptide as positive identifications. Single peptide identifications were accepted only if the peptide was a unique identifier and had occurred in all four replications of protein samples.

\section{Protein identification and sequence informatics}

Sequences of matched/identified poplar proteins were further used in BLAST searches against UniProt Knowledgebase http://www.uniprot.org or the NCBI non-redundant database http://www.ncbi.nlm.nih.gov/ blast using the BLOSUM62 algorithm. An E-value cutoff of $1.0 \times \mathrm{e}^{-5}$ was used to find similar proteins in other plant species. A similar protein with the highest degree of sequence similarity was considered as the protein identity/similarity. If several poplar proteins matched to the same gel spot and their sequences produced the same BLASTP output (e.g., the same best matching similar protein, but with a different degree of sequence similarity to poplar protein), we only considered the hit with the highest Mascot score, which was always the $1^{\text {st }}$ rank hit. Identified poplar proteins were assigned putative biological function based on Gene Ontology Annotation [120] of their most similar proteins from other species or based on literature. For easy interpretation, the annotated proteins were then clustered into general biological categories that were identified based on common terminology used in literature. Poplar protein sequences were also screened for the presence of signal peptides using SignalP [31,121] and for non-classical signal peptide using SecretomeP [32]. Phosphorylation sites on proteins were predicted using NetPhos 2.0 [37]. Protein identifications were submitted to the Protein Identifications (PRIDE) database, accession numbers 14841-14844.

\section{Determining post-translational modifications}

Five hundred micrograms of leaf apoplast proteins from one of the sexually mature $P$. deltoides trees were separated by 2-D PAGE as described above. After electrophoresis, gels were stained with Pro-Q Diamond and Pro-Q Emerald 488 to detect phosphorylated and glycosylated proteins, respectively. In both cases, manufacturer's (Molecular Probes, Carlsbad, CA) staining protocols were followed, and gels were scanned using the Typhoon 9410 imager. Gels were subsequently poststained with SYPRO Ruby (Molecular Probes, Carlsbad, CA) for visualizing total proteins and re-scanned with the Typhoon 9410 imager.

\section{Microarray experiments}

To determine year-round gene expression patterns corresponding to leaf apoplast proteins throughout leaf development, three independent replications of leaf tissues at each collection period were sampled from the upper crown of one of the sexually mature $P$. deltoides trees $2 \mathrm{~h}$ after sunrise and kept on ice. We used one genotype to have a uniform data set, because gene expression often significantly varies among poplar genotypes. We confirmed the results of our microarray experiments via qRT-PCR using two other sexually mature $P$. deltoides trees. Tissue collections were conducted in September 2005, December 2005, February 2005, March 2005, March 2006, April 2006, May 2006, 
and June 2006, spanning the development of leaves and four seasons, as well as overlapping with the timing of sample collection for apoplast proteome analysis. Leaves were preformed and enclosed in terminal vegetative buds in September, December, February, and March (Figure 2A; [122]). Leaves began unfolding from terminal buds late March, and this process continued by late May when leaves became fully expanded and mature (Figure 2A). Thus, we reorganized the samples based on leaf development, beginning with September and ending with June. We conducted array experiments in two 12chip sets. The first set included September 05, December 05, February 05, and March 05, whereas the second set consisted of March 06, April 06, May 06, and June 06. Thus, the March samples (6 independent sampling) provided an overlap between the two sets. We used the poplar arrays from the same batch, and followed the same protocol executed by the same person.

Total RNA was isolated using a hot-borate extraction method [123], followed by DNase I digestion and cleanup using the RNeasy Mini Kit (Qiagen, Valencia, CA). A total of $3 \mu \mathrm{g}$ of total RNA from each sample was used to synthesize the double-strand cDNA using the Onecycle cDNA Synthesis Kit (Affymetrix, Santa Clara, CA). After cleaning-up the double-strand cDNA using the Sample Cleanup Module (Affymetrix, Santa Clara, CA), the biotin-labeled cRNA was synthesized from the double-strand cDNA via in vitro transcription using the Genechip IVT Labeling Kit (Affymetrix). cRNA (20 $\mu \mathrm{g})$ was fragmented at $94^{\circ} \mathrm{C}$ for 35 minutes. Fifteen micrograms of the fragmented cRNA were used to hybridize each Genechip Poplar Genome Array (Affymetrix) in Genechip Hybridization Oven 640 (Affymetrix) at $45^{\circ} \mathrm{C}$ for $16 \mathrm{hr}$. The arrays were washed using the Genechip Fluidics Station 450 (Affymetrix) and then scanned using the Genechip Scanner 3000 (Affymetrix). Microarray data were submitted to the National Center for Biotechnology Information Gene Expression Omnibus (GEO) GSE24349.

Quality control (QC) assessment, data processing, and statistical analysis of array data were conducted in $\mathrm{R}$ [124] using packages from the Bioconductor project [125]. QC assessment using affycoretools [126] showed that a block effect existed between the first set of samples (September, December, February, and March) and the second set of samples (March, April, May, and June) even after processing the arrays with the GCRMA algorithm [127]. In addition to background-correction and summarizing the multiple probes into one probe set value, GCRMA does a quantile normalization between arrays, but no normalization method can completely remove some block effects. In these cases, the block effect must also be accounted for in a statistical model. A one-way ANOVA for time was performed, taking the correlation due to block into account, using the limma package [128]. The limma model was fit using all 61,413 probe-sets on the array because it uses an empirical Bayes correction [129] that helps to improve power by borrowing information across genes. Expression values for each time point (adjusted for batch effects) were pulled for the model for the 139 probe sets matched to our leaf apoplast proteins of interest (see below).

Expression patterns over time were represented as the $\log 2$ fold-change of each time point to the baseline time point (September), and hierarchical clustering was performed on the 139 probe sets corresponding to 139 leaf apoplast proteins. To determine which of these clusters represented co-expressed modules, we used the "Dynamic Hybrid" algorithm from the dynamicTreeCut package [130]. A total of nine modules were found with deepSplit $=2$. However, two of the modules had extremely similar expression patterns and were merged into one module (yellow, Figure 4A).

\section{Matching proteins to microarray probe sets}

Affymetrix's poplar genome array contains over 61,000 probe sets that were designed from UniGene Build \#6 (March 16, 2005; Populus tremula x Populus tremuloides only), GenBank ${ }^{\circledR}$ mRNAs and ESTs (April 26, 2005; all Populus species), and the predicted gene set v1.1 from the Populus genome project (May 4, 2005; P. trichocarpa). The annotation information for the probe sets provided by Affymetrix is primarily based on UniGene and GenBank IDs, not DOE Joint Genome Institute's gene model names or protein/transcript IDs, because probe sets are based on the sequence data available at the time. However, our knowledge of which sequences actually uniquely represent a particular gene and which sequences may be common to related genes (i.e., annotation) is constantly changing. Therefore, there can be complex, many-to-many relationships between probe sets and Gene Models.

To find the "best" probe set on the array for each of our 144 proteins of interest from leaf apoplast, we used two other annotation sources: the PopARRAY database http://aspendb.uga.edu/poparray; February 4, 2009] and a custom annotation of the Affymetrix poplar array kindly provided by $\mathrm{K}-\mathrm{H}$. Han and J-H. Ko at Michigan State University (January 9, 2009). Using both sources, a total of 253 probe sets mapped to our 144 leaf apoplast proteins. We additionally used the PopARRAY database to reverse map the 253 probe sets to poplar gene models, and 212 mapped to only one gene model. We refer to these 212 as "unique-hit" probe sets whereas the other 41 are "multi-hit" probe sets. We used the following criteria to select one "best" probe set for each of our proteins. If one unique-hit probe set was found in both sources, we used it. If more than one unique-hit probe 
set was found in both sources, we used one with the lowest raw $p$-value from the ANOVA model. If no unique-hit probe set was found in both sources, we used the source that had a unique-hit probe set. If more than one unique-hit probe set in that source, we used the one with the lowest raw $p$-value from the ANOVA model. If no unique-hit probe sets were found in either source, we used multi-hit probe sets following the same criteria. Using these criteria, we were able to find unique-hit probe sets for 118 proteins, multi-hit probe sets for 21 proteins, and no matching probe sets for 5 proteins.

\section{Validation of microarray results}

Validation of randomly selected seven genes in the microarray data was conducted via qRT-PCR using leaves from two other sexually mature $P$. deltoides trees (Tree 1 and Tree 2). Three replications of leaf tissues at each collection were sampled monthly from March to October $2 \mathrm{~h}$ after sunrise. Total RNA was isolated as previously described, and the first-strand cDNA was synthesized using $1 \mu \mathrm{g}$ of total RNA in a total of $20-\mu \mathrm{l}$ reaction mixture as described by Hsu et al [131]. qRTPCR was conducted using the Power SYBR Green PCR Master Mix Kit (ABI, Applied Biosystems, Foster City, CA) and the 7500 Fast Real-Time PCR system (ABI, Applied Biosystems) with a run mode of "Standard 7500". Gene specific primers (Additional file 15: Table S9) were designed according to available sequences from the poplar database http://genome.jgi-psf.org/Poptr1_1/ Poptr1_1.home.html. Since we used the primers on $P$. deltoides cDNA, the amplicons were sequenced and a BLAST analysis was conducted against the poplar genome database to confirm the gene IDs. The $P$. deltoides UBIQUITIN $(U B Q)$ transcript was used as an internal standard. Each qRT-PCR reaction mixture contained 0.5 $\mu \mathrm{l}$ of cDNA template, $5 \mu \mathrm{l}$ of SYBR Green Mix, $0.25 \mu \mathrm{l}$ of $10 \mu \mathrm{M}$ forward primer, $0.25 \mu \mathrm{l}$ of $10 \mu \mathrm{M}$ reverse primer, and $4 \mu \mathrm{l}$ of $\mathrm{dd}_{2} \mathrm{O}$. The PCR was programmed to run an initial incubation at $95^{\circ} \mathrm{C}$ for $10 \mathrm{~min}$, followed by $95^{\circ} \mathrm{C}$ for $15 \mathrm{sec}$ and $60^{\circ} \mathrm{C}$ for $1 \mathrm{~min}$ for a total of 40 cycles. A dissociation curve analysis was conducted after each run to verify the specificity of amplicon and the formation of primer-dimers. A standard curve was generated by log [cDNA] (represented by the amount of total RNA used in the real-time reaction) versus the crossing point value using a series of dilutions of the first-strand cDNA. The ratio between the expression levels of each transcript and $U B Q$ for each sample was calculated using the relative quantitative analysis method based on a formula for the standard curve assay. Each assay was repeated at least three times. Then, these expression data were compared with those first elucidated from our microarray analysis. Linear regression was used in which the qRT-PCR ratios (amount of target gene/amount of UBIQUITIN) were used as predictors of normalized microarray intensity values (transformed with $\log 2$ ) for each respective gene. This analysis was performed separately for Tree 1 and Tree 2 .

\section{Water stress experiments and transcript analysis}

P. deltoides 'WV94' plantlets were transferred from tissue culture in November 2006 to leach tubes containing peat, vermiculite, and perlite in a 2:2:1 ratio, and initially fertilized with Osmocote, bone meal, gypsum, and dolomite at $12,4,4$, and $0.5 \mathrm{ml} / \mathrm{L}$, respectively. The transplants were grown in a mist bed for two weeks, and then transferred to greenhouse $\left(26 / 21^{\circ} \mathrm{C}\right.$ day/night $)$ with a photoperiod of 14-16 h. After 12 weeks, plants were transplanted to $3.8 \mathrm{~L}$ containers using the same potting media, and placed in greenhouses $\left(19^{\circ} \mathrm{C} /\right.$ day with no supplemental lighting). Plants were fertilized with Peter's 20-20-20 at $300 \mathrm{ppm}$ per month. Plants were grown until they reached an average height of $81.1 \mathrm{~cm}$. A total of 20 plants were used for the cyclical water stress (drought) experiment, which commenced on 4/13/2007 and concluded on 5/14/2007. Water stress included 4 cycles in which water was withheld from plants for a period, and then watering was resumed. 10 plants were sampled after two cycles of drought, and 10 were sampled after 4 cycles of drought. Of the 10 plants, four were controls and six were water stressed. A completely randomized design was used in greenhouse. Pre-dawn water potential measurements were taken each night. During cycles 1 and 3, plants were watered again after water potential measurements indicated that plants were experiencing moderate water stress $(<0.05-1.0 \mathrm{MPa})$. During cycles 2 and 4, partially-expanded leaves were sampled when the water potential measurements indicated that the plants, on average, were under a moderate level of water stress. Water was then withheld from the plants until water potential measurements indicated that the plants were under severe water stress $(<1.0$ $\mathrm{MPa}$ ). Partially-expanded leaves were collected from each plant, and watering was resumed. The total number of samples collected after 4 cycles was 32 (4 control samples, 6 moderately-stressed samples, and 6 severelystressed samples per cycle, i.e., cycle 2 and 4).

Total RNA was extracted from 32 partially expanded leaf samples, using the Spectrum ${ }^{\text {Tw }}$ Plant Total RNA Kit (Sigma). An on-column DNase I treatment (Sigma) was conducted during the RNA extraction according to the provided protocol. cDNA synthesis was conducted using a SuperScript ${ }^{\circ}$ III First-Strand Synthesis SuperMix for qRT-PCR (Invitrogen) according to the protocol provided. One microgram of total RNA was used for cDNA synthesis in a $20-\mu l$ reaction mixture. After cDNA synthesis, all cycle 2 control plants were pooled, all 
cycle 2 moderately-stressed samples were pooled, and all cycle 2 severely-stressed samples were pooled. The same was also done with the cycle 4 samples, resulting in a total of six samples for real-time qRT-PCR.

Following the selection of genes of interest based on the annotation of stress-related pathways from leaf apoplast proteome, qRT-PCR was used to compare the expression of 16 genes across the six samples. Amplification reactions $(25.0 \mu \mathrm{l})$ were carried out using $\mathrm{iQ}^{\mathrm{TM}}$ SYBR $^{\circledR}$ Green Supermix according to instructions provided by Bio-Rad Laboratories. Each reaction contained a cDNA template $(1.0 \mu \mathrm{l}), \mathrm{SYBR}^{\otimes}$ Green supermix $(12.5 \mu \mathrm{l})$, sterile water $(8.5 \mu \mathrm{l})$, and the appropriate forward and reverse $5 \mu \mathrm{M}$ primer pair (1.5 $\mu \mathrm{l}$ each). An actin gene (ACT) expressed at a constant rate across tissue types was used as a control to normalize the data for differences in input RNA and efficiency of reverse transcription between the samples. PCR amplification reactions were performed in triplicate. The thermal cycling conditions took place on the StepOne ${ }^{\mathrm{Tm}}$ Plus Real Time PCR detection system (Applied Biosystems) and included 3 minutes at $95^{\circ} \mathrm{C}, 40$ cycles of $95^{\circ} \mathrm{C}$ for 15 seconds, $55^{\circ} \mathrm{C}$ for 20 seconds and $72^{\circ} \mathrm{C}$ for 20 seconds, 1 minute at $95^{\circ} \mathrm{C}, 80$ cycles at $55^{\circ} \mathrm{C}$ for 10 seconds with the temperature increasing by $0.5^{\circ} \mathrm{C}$ after each cycle and then a hold at $4^{\circ} \mathrm{C}$ until plates were removed from the machine. The forward and reverse primers that were used to detect gene expression are shown in additional file 15: Table S9.

Data analysis was carried out using StepOne ${ }^{\mathrm{rm}}$ Software (Applied Biosystems). Cycle threshold values that were flagged because they did not meet default $\mathrm{QC}$ requirements were removed from the analysis. Relative gene expression, or fold-change, was calculated for each gene with the cycle control sample used as the reference sample. Therefore, gene expression in the control always equaled 1 . Values greater than 1 represent up-regulation, and values less than 1 represent down-regulation. Fold change minimum and maximum calculations were based on one standard deviation.

\section{Pathogen challenge experiments and transcript analysis}

Individual trees of the hybrid poplar clone NM6 (Populus nigra $\mathrm{X}$ Populus maximowiczii) were initially obtained from in vitro grown plantlets and then transferred to a growth chamber with the following environmental conditions: $26^{\circ} \mathrm{C} / 22^{\circ} \mathrm{C}$ day/night, 16 -h day, $60 \%$ relative humidity, and $100 \mu \mathrm{mol} \mathrm{m} \mathrm{m}^{-2} \mathrm{~s}^{-1}$ light intensity. Plants were fertilized every other week with 20:20:20 N: P: K $(1 \mathrm{~g} / \mathrm{L})$. Leaves LPI 8 and LPI 9 (leaf plastochron index, [132]) were used for all experiments from $1 \mathrm{~m}$ tall poplar trees (16 fully expanded leaves). Inoculation of leaf discs with Melampsora was conducted as previously described [133]. Briefly, disks of $2 \mathrm{~cm}$ in diameter were inoculated on the abaxial side with M. medusae f. sp. deltoidae or M. laricipopulina at a density of 1,000-3,000 spores (in $0.01 \%$ Tween) per $\mathrm{cm}^{2}$. After inoculation, the disks were kept on wet paper in large Parafilm sealed Petri dishes $(22 \mathrm{~cm} \times 22 \mathrm{~cm})$ and incubated in a growth chamber at $18^{\circ} \mathrm{C}$ with a long photoperiod. Control disks were sprayed with Tween $0.01 \%$. Samples for pathogen quantification and transcript analysis were collected at different time points over 10 days after inoculation. Tissues were collected from four biological replicate trees and processed separately for each treatment and time point.

Leaf disks were taken at specified intervals and frozen in liquid nitrogen. $100 \mathrm{mg}$ of ground leaf-disk powder were used for either DNA or RNA extractions. Total genomic DNA preparation was performed by using the Plant DNeasy Kit (QIAGEN) following manufacturer instructions. Pathogen growth was quantified as described previously [133]. Amplifications were performed using a Stratagene Mx3000p apparatus (Agilent Technologies, Santa Clara, CA) and $1 \times$ QuantiTect SYBR $^{\circledR}$ Green mixture (Qiagen).

RNA was isolated using the Qiagen RNeasy Kit by following the manufacturer's instructions. RNA was treated with a DNase I, and complementary DNA was synthesized from the RNA samples (500 ng) for single strand conversion to cDNA using reverse transcriptase (Invitrogen, SuperScript ${ }^{\mathrm{Tm}}$ II) and oligo-dT primers. Resulting samples were not treated with RNase $H$, and cDNAs were diluted at $5 \mathrm{ng} / \mu \mathrm{l}$. We selected the genes of interest based on the annotation of stress-related pathways from leaf apoplast proteome. Gene specific primers (Additional file 15: Table S9) were designed according to available sequences from the NCBI Entrez Nucleotide database http://www.ncbi.nlm.nih.gov and from the poplar genome database. Amplifications were performed using a Stratagene Mx3000p apparatus (Agilent Technologies, Santa Clara, CA) and $1 \times$ QuantiTect SYBR Green mixture (Qiagen). Primer specificity was tested on NM6 genomic DNA (P. trichocarpa, P. Nigra, $P$. maximowiczii) and used at a concentration of $0.6 \mu \mathrm{M}$. Each PCR reaction had a $25-\mu \mathrm{l}$ volume and contained $0.6 \mu \mathrm{M}$ of forward and reverse primers, $10 \mathrm{ng}$ of cDNA as template, and $1 \times$ master mix solution (Quanti Tect Tm Sybr@ Green PCR Kit, Qiagen inc., Valencia, CA). Using the SYBR Green amplification mode in Stratagene's software, PCR cycling conditions were $15 \mathrm{~min}$ incubation at $95^{\circ} \mathrm{C}$, followed by 40 successive cycles $\left(94^{\circ} \mathrm{C}\right.$ for $15 \mathrm{sec}$, annealing and extension between $57^{\circ} \mathrm{C}$ and $65^{\circ} \mathrm{C}$ for $2 \mathrm{~min}$, depending on the primer set and target gene). Primer efficiency and number 
of molecules were determined using the No-Ct-Linear Regression of Efficiency (LRE) from fluorescence and $\mathrm{Ct}$ values [134]. Gene expression was presented as fold change observed between treatments relative to control samples based on a modified Livak and Schmittgen [135] calculation $\left(2^{-\Delta \Delta C t}\right)$ to introduce efficiency (E). Internal control gene-stability measure was evaluated for poplar actin, elF4, ubi10, gadph, and cdc2 following a previously described normalization method (Additional file 16: Figure S7; [136]).

\section{Light microscopy}

Tissues from pressurized and control leaves of three mature trees were fixed in half-strength Karnovsky's fixative (2\% paraformaldehyde and $2.5 \%$ glutaraldehyde) with phosphate buffer (0.1 M, pH 7.2; [131]). Samples were then rinsed in distilled water and dehydrated in a graded ethanol series. Leaf pieces were infiltrated and embedded in Paraplast Plus (Oxford Labware, St. Louis, MO) using CitriSolve (Fisher Scientific, Houston, TX) as a transitional fluid. Serial 8 micron sections were cut with an American Optical 820 rotary microtome (Fisher Scientific, Houston, TX) and were stained with saffranin and fast green. All the thin sections were examined for ruptured cells in the vicinity of stomata and within the vasculature on an Olympus BX60 light microscope (Olympus America Inc., Center Valley, PA).

\section{Immunoblot analysis}

Protein samples extracted from leaf apoplast fluid and whole leaf tissue of three sexually mature trees were resuspended in SDS-PAGE loading buffer [62.5 mM Tris- $\mathrm{HCl}, \mathrm{pH} 6.8 ; 10 \%(\mathrm{v} / \mathrm{v})$ glycerol; $2 \%(\mathrm{w} / \mathrm{v})$ SDS; and $720 \mathrm{mM} \beta$-mercaptoethanol] and quantified with the 2-D Quant Kit (Amersham Biosciences). Fifty micrograms of total proteins from each sample were separated on SDSPAGE using $4 \%$ stacking and $12 \%$ separating polyacrylamide gels. Protein samples were subsequently blotted onto a nitrocellulose membrane (Sigma, St. Louis, MO) using a semi-dried electro-transferring blotter (Owl Separation Systems, Portsmouth, NH). The rbcL (Ribulose-1,5-bisphosphate carboxylase/oxygenase large subunit) and malate dehydrogenase (cMDH) proteins, which are symplastic [25], were detected using the ECL Western Blotting Analysis System (Amersham Biosciences) according to the manufacturer's instructions. Monoclonal primary antibodies for rbcL (Cosmo Bio, Tokyo, Japan) were used in a dilution ratio of 1:5,000 for hybridization. A dilution ratio of 1:7,500 was used for cMDH (Santa Cruz Biotechnology, Santa Cruz, CA).

\section{Nutrient analysis}

Three replications of $1.5 \mathrm{ml}$ leaf apoplast fluid per sexually mature tree were used for nutrient analysis. Extracts were stored at $-70^{\circ} \mathrm{C}$ until analysis commenced and were thawed immediately before use. Congruently, three samples of whole leaves were harvested from each tree for nutrient analysis. Leaf samples were dried at $50^{\circ} \mathrm{C}$ for $48 \mathrm{~h}$ and ground into a fine powder. Two hundred milligrams of leaf tissues were placed in a porcelain crucible, placed in a furnace, and ashed at $500^{\circ} \mathrm{C}$ for $4 \mathrm{~h}$. The samples were then allowed to cool to room temperature. Ash was gently mixed with $1 \mathrm{ml}$ of hydrochloric acid and deionized water solution $(1: 1 \mathrm{v} / \mathrm{v})$ and allowed to dissolve for $1 \mathrm{~h}$. Subsequently, liquid was decanted through $2 \mathrm{~mm}$ and $1 \mathrm{~mm}$ screens, respectively, for $1 \mathrm{~h}$, and the solution was collected. Nutrient concentrations (Ca, K, Mg, Na, P, Cu, $\mathrm{Fe}, \mathrm{Mn}$, and $\mathrm{Zn}$ ) from the whole leaf extract and the undiluted apoplast fluid were determined spectrophotometrically using an inductively coupled plasma (ICP) emission spectrophotometer (Thermo Jarrel Ash Iris Advantage ICP, Houghton, MI). There were three technical replications taken from each of the three biological replications. Concentrations were estimated for leaf $(\mathrm{mg} / \mathrm{g})$ and apoplast fluid (mg/l). Apoplast fluid density was estimated to be approximately one based on three mass measurements. Leaf and apoplast fluid nutrient measurements were then converted to a standard unit of parts per million (ppm). A mixed general linear model was used to compare the concentrations between the fixed tissue type effect and the random biological repeat (tree) effect.

\section{Abscisic acid analysis}

Three independent leaf samples (\#9-11 from the base of a shoot) from the upper crown of a sexually mature tree were collected $2 \mathrm{~h}$ after sunrise at each collection time from April to July in 2007. One gram (fresh weight) of leaves was ground into powder which was then freezedried using a SpeedVac (LABCONCO, model LYPHLOCK 6). 100-150 mg (dry weight) of sample was used for determining the concentration of abscisic acid by following the procedure detailed in Destefano-Beltrán et al [137].

\section{Phylogenetic analysis}

Full-length (predicted) alcohol dehydrogenase protein sequences were retrieved from the poplar database http://genome.jgi-psf.org/Poptr1_1/Poptr1_1.home.html. New poplar IDs were obtained from http://www.phytozome.net/poplar (Version 2.0 of the poplar assembly and annotation). Arabidopsis full-length (predicted) alcohol dehydrogenase proteins were obtained from the Arabidopsis database http://www.arabidopsis.org by conducting protein-protein BLAST using the protein sequence for poplar apoplast alcohol dehydrogenases. At2g47140 was used to root the tree. To construct the phylogenetic tree for peroxidases, protein sequences of peroxidases for other species were obtained from NCBI http://www.ncbi.nlm.nih.gov. Short sequences were 
excluded. For creating multiple alignments and constructing and visualizing the phylogenetic trees, we followed the procedure outlined in Hsu et al [131].

\section{Construction of regulatory networks and pathways}

Unique poplar protein identification numbers from shoot and leaf apoplast were compiled with those from root apoplast [22]. These proteins (144 from leaf, 135 from stem, and 97 from root) were imported into Pathway Studio (Ariadne Genomics, Rockville, MD). These protein IDs were associated to homologs based on a poplar-to-Arabidopsis mapfile. Briefly, this file was created by blasting poplar proteins against the Arabidopsis genome. Appropriate homologs were selected based on best e-value and greatest similarity. After import, 165 proteins from root, stem, and leaf tissues were successfully matched with proteins described in the ResNet Plant Database 2.0. A pathway was then constructed based on established connections in ResNet Plant Database 2.0 with other proteins, small molecules, treatments, and plant processes. The initial pathway was extremely large and had many pathway branches not connected with physiological process of pertinence to our study. Thus, pathway thinning was conducted. First, plant processes not related to stress response were discarded. Second, connections were discarded if our proteins were not directly in the connection or upstream (e.g., direct connection between treatment and plant process). A final re-analysis of the pathway was conducted to ensure all objects were still connected to the main pathway. Any objects that became disconnected because of the previous two thinning regimes were subsequently deleted. Finally, proteins were positioned and color coded based on the tissue(s) in which they occurred.

\section{Additional material}

Additional file 1: Supplementary Figure S1. 2-D protein reference maps of $P$. deltoides leaf and stem apoplast. (A) Leaf apoplast proteins $(1 \mathrm{mg})$ were resolved on 2-D PAGE and visualized with colloidal Coomassie Blue G-250 stain. Corresponding proteins in spots with numbers are given in additional file 2: Table S1. Protein molecular weights are shown in kilodaltons $(\mathrm{kDa})$. (B) Representative 2-D reference map for stem apoplast proteome. Proteins were resolved on 2-D PAGE and visualized with Deep Purple Total Protein Stain. Corresponding proteins in spots with numbers are given in additional file 4: Table S3. Protein molecular weights are shown in kilodaltons $(\mathrm{kDa})$.

Additional file 2: Supplementary Table S1. Proteins identified in poplar (P. deltoides) leaf apoplast using 2-D PAGE MS/MS.

Additional file 3: Supplementary Table S2. Proteins identified in poplar (P. deltoides) leaf apoplast using 2-D LC MS/MS.

Additional file 4: Supplementary Table S3. Proteins identified in poplar (P. deltoides) stem apoplast using 2-D PAGE MS/MS.

Additional file 5: Supplementary Table S4. Proteins identified in poplar (P. deltoides) stem apoplast using 2-D LC MS/MS.
Additional file 6: Supplementary Figure S2. Staining of leaf apoplast proteins to identify post-translational modifications. (A) Leaf apoplast proteins stained with ProQ-Emerald 488 (left panel) to detect glycosylated proteins. The same gel was post-stained with SYPRO Ruby (right panel) to visualize all proteins. Boxed spots annotated with letters indicate glycosylated proteins whose IDs are given in additional file 2 : Table S1. Protein molecular weights are shown in kilodaltons ( $\mathrm{kDa}$ ). (B) Leaf apoplast proteins stained with ProQ-Diamond (left panel) to detect phosphorylated proteins. The same gel was post-stained with SYPRO Ruby (right panel) to visualize all proteins. Boxed spots annotated with letters indicate phosphorylated proteins. Box a corresponds to cysteinerich repeat secretory protein 38 (spot 14; POPTR_1698s00200.1; additional file 2: Table S1), whereas box $b$ refers to thaumatin-like protein (POPTR_0018s10490.1; spot 88; additional file 2: Table S1). Protein molecular weights are shown in kilodaltons ( $\mathrm{kDa})$.

Additional file 7: Supplementary Figure S3. Cluster analysis of yearround expression profiles of genes corresponding to 139 leaf apoplast proteins shown in Figure 4A. The log2 fold-change (FC) is shown on the left. Dotted lines (black) denote the expression profiles of individual genes, whereas the solid lines (red) represent the mean expression for the cluster. For each time point, boxplot representation of the expression profile for all filtered array elements is provided.

Additional file 8: Supplementary Figure S4. Validation of microarray data via GRT-PCR using leaves from two other sexually mature $P$. deltoides trees (Tree 1 and Tree 2), predictive significance ( $p$-value) and relationship strength $\left(R^{2}\right.$ value) with microarray intensity values. (A) Alcohol dehydrogenase 2 (POPTR_0002s07290.1): For Tree $1, p=0.007$ and $R^{2}=$ 0.54 ; For Tree $2, p=0.16$ and $R^{2}=0.19$. (B) Abscisic acid (ABA) analysis in poplar (P. deltoides) leaves in April, May, June, and July. (C) Cationic peroxidase 1 (POPTR_0016s14030.1): For Tree 1, $p=0.164$ and $R^{2}=0.18$; For Tree $2, p=0.019$ and $R^{2}=0.44$. (D) Thaumatin-like protein (POPTR_0018s10490.1): For Tree 1, $p<0.001, R^{2}=0.88$; For Tree 2, $p=$ 0.003 and $R^{2}=0.59$. (E) Blight-associated p12 (POPTR_0006s 19310.1): For Tree $1, p=0.06, R^{2}=0.30$, For Tree $2, p=0.016$ and $R^{2}=0.46$. (F) Phenylcoumaran benzylic ether reductase (POPTR_0002s03580.1): For Tree1, $p=0.002, R^{2}=0.64$; For Tree $2, p=0.51$ and $R^{2}=0.042$. (G) Dehydration stress-induced protein (POPTR_0007s05650.1): For Tree 1, $p=$ 0.001 and $R^{2}=0.65$; For Tree 2, $p<0.001$ and $R^{2}=0.78$. $(H)$ Woundresponsive (POPTR_0010s16050.1): For Tree $1, p=0.04, R^{2}=0.35$; For Tree $2, p=0.7$ and $R^{2}=0.014$.

Additional file 9: Supplementary Table S5. Clusters of year-round expression profiles of genes corresponding to 139 leaf apoplast proteins and their functional annotation.

Additional file 10: Supplementary Figure S5. Phylogenetic analysis of alcohol dehydrogenase proteins in poplar (POPTR) and Arabidopsis thaliana (At). Poplar leaf (POPTR_0005s06140.1 and POPTR_0002s07290.1 in purple) and root (POPTR_0008s16150.1 in red) apoplast alcohol dehydrogenases fall into different clades.

Additional file 11: Supplementary Table S6. Modeling leaf, shoot, and root apoplast proteomics data into regulatory networks and pathways via Pathway Studio using prior knowledge. This pathway contains

treatments, primary proteins, effect of primary proteins, and secondary effect leading back to another protein or small molecule. Proteins are referenced by their protein functional name/abbreviation followed by poplar ID in parenthesis (old, new). Effect type is indicated by $-+>,-\mid$, or $\rightarrow$, meaning a strong positive, strong negative, or unresolved association, respectively. Abbreviations: SCPL20 = serine carboxypeptidase-like 20, PR5 = pathogenesis-related gene 5, KCS10 = 3ketoacyl-CoA synthase 10, SIZ1 = E3 SUMO-protein ligase SIZ1, CP1 = cysteine-type peptidase, $\mathrm{SOD}=$ superoxide dismutase, $\mathrm{PGK}=$ phosphoglycerate kinase, GST = glutathione S-transferase, SAM = Sadenosylmethionine synthetase, $\mathrm{CH}-\mathrm{IV}=$ Class IV chitinase, $\mathrm{TPI}=$ triosephosphate isomerase, $\mathrm{DHAR}=$ dehydroascorbate reductase, $\mathrm{BGL2}=$ beta-1,3-glucanase 2, TIM = triosephosphate isomerase, GAD = glutamate decarboxylase, and ICDH = isocitrate dehydrogenase.

Additional file 12: Supplementary Table S7. List of poplar apoplast proteins and corresponding transcripts and their expression levels in publicly available poplar (Populus spp.) microarray data obtained from 
stressed poplar tissues [59,60,141,142]. Dpi, Days Post Infection; Mlp, Melampsora larici-populina; Mmd, Melampsora medusae f. sp. deltoidae.

Additional file 13: Supplementary Figure S6. Phylogenetic analysis of peroxidases from various plant species, including the poplar apoplast peroxidases. Protein sequences of 18 poplar apoplastic POXs and 30 deduced amino acid sequences for the following POXs from other species were used for phylogenetic analysis: Arabidopsis At5g06720 (A. thaliana AtPA2; Q42578), Arabidopsis At3g49120 (A. thaliana AtPCb; Q9SMU8), Arabidopsis At3g49110 (A. thaliana AtPCa; P24101), tobacco TP60 (Nicotiana tabacum; Q9XFL2), tomato TPX1 (Lycopersicon esculentum; Q07446), tomato TPX2 (L. esculentum; Q07445), cotton pod2 (Gossypium hirsutum; Q8RWW0), cotton pod3 (G. hirsutum; Q8RVP7), cotton pod4 (G. hirsutum; Q9XGV6), cotton pod6 (G. hirsutum; Q8RVP4), rice POX8.1 (Oryza sativa; O22439), rice POX22.3 (O. sativa; O22438), rice POC1 (O. sativa; Q9LKY9), Norway spruce SPI2 (Picea abies; Q9SC55), Norway spruce PX1 (P. abies; Q5W5I3), Norway spruce PX2 (P. abies; Q5W514), Norway spruce PX3 (P. abies; Q5W512), sweet potato swpa4 (Ipomoea batatas; B3SHI1), sweet potato swpb5 (I. batatas; B3SHI2), sweet potato swpb7 (I. batatas; B3SHIO), bell pepper PO2 (Capsicum annuum; A4ZC16), poplar POD1 (Populus alba $\times$ Populus tremula var. glandulosa; Q58GF4), lombardy poplar CY26 (P. nigra; Q40949), western balsam poplar PXP3-4 (P. trichocarpa; Q43101), white poplar CWPO-C (P. alba; Q4ADU9), white poplar PO1 (P. alba: Q50KBO), white poplar PO2 (P. alba; Q08IT5), white poplar PO3 (P. alba; Q08IT6), aspen prxA1 (P. kitakamiensis; Q43055), aspen prxA3a (P. kitakamiensis; Q43049). A. thaliana L-ascorbate peroxidase 1, cytosolic (At1g07890/APX1; Q05431) was used to root the tree.

Additional file 14: Supplementary Table S8. N-terminal sequencing of proteins from three spots $(83,87$, and 88$)$ on leaf apoplast 2-D gels. Letters correspond to amino acids. Dashes indicate undetermined residues.

Additional file 15: Supplementary Table S9. List of primers that were used for qRT-PCR analyses.

Additional file 16: Supplementary Figure S7. Using qRT-PCR, the transcript stability of potential internal control genes was determined using leaf tissues of the hybrid poplar clone NM6 ( $P$. nigra X $P$. maximowiczii) challenged with the isolates of $M$. medusae $\mathrm{f}$. $\mathrm{sp}$. deltoidae (Mmd) and M. laricipopulina (Mlp).

\section{Acknowledgements}

We thank Y. Kang, M. Monroe, G. Pelletier, K-H. Han, and J-H. Ko for assistance, and J. Kreuzwieser, V. Chiang, and S. Strauss for discussions on the manuscript. MS was conducted at the Life Sciences and Biotechnology Institute, Mississippi Agricultural and Forestry Experiment Station, Mississipp State University. S.J. and T.J.T. were supported by the U.S. Department of Energy, Office of Science, Biological and Environmental Research. Oak Ridge National Laboratory is managed by UT-Battelle, LLC, for the U.S. Department of Energy under contract DE-AC05-00OR22725. This work was funded by NSF (DBI-0501890 and IOS-0845834) to C. Y.

\section{Author details}

'Department of Forestry, Mississippi State University, Mississippi State, MS 39762 USA. ${ }^{2}$ Life Sciences and Biotechnology Institute, Mississippi Agricultural and Forestry Experiment Station, Mississippi State University, Mississippi State, MS 39762 USA. ${ }^{3}$ W.M. Keck Center for Comparative and Functional Genomics, University of Illinois, Urbana, IL 61801 USA. ${ }^{4}$ Environmental Sciences Division, Oak Ridge National Laboratory, Oak Ridge, TN 37831 USA. ${ }^{5}$ USDA-ARS, Mississippi State, MS 39762 USA. ${ }^{6}$ USDA-ARS, Fargo, ND 58105 USA. ${ }^{7}$ Electron Microscopy Center, Mississippi State University, Mississippi State, MS 39762 USA. ${ }^{8}$ Natural Resources Canada, Canadian Forest Service, Laurentian Forestry Centre, 1055 du P.E.P.S., P.O. Box 10380, Stn. Sainte-Foy, Quebec, Quebec G1V 4C7, Canada.

\section{Authors' contributions}

$\mathrm{CY}, \mathrm{OP}, \mathrm{C}-\mathrm{YH}, \mathrm{JPA}, \mathrm{JD}, \mathrm{AA}, \mathrm{JCS}, \mathrm{TJT}, \mathrm{AML}$, and AS designed research; OP, C$Y H, J P A, T P, L V, J D, S J, A M L, A S$, and CY performed research; OP, C-YH, JPA,
TP, JD, AA, JCS, TJT, AS, and CY analyzed data; CY, OP, C-YH, and JPA wrote the paper. All authors read and approved the final manuscript.

Received: 28 June 2010 Accepted: 29 November 2010

Published: 29 November 2010

\section{References}

1. Braatne JH, Rood SB, Heilman PE: Life history, ecology, and conservation of riparian cottonwoods in north America. In Biology of Populus. Edited by: Stettler RF, Bradshaw Jr HD, Heilman PE, Hincley TM. Ottawa, Canada: NRC Research Press; 1996:57-85.

2. Parolin P: Submerged in darkness: adaptations to prolonged submergence by woody species of the Amazonian floodplains. Ann Bot 2009, 103:359-376.

3. Rood SB, Braatne JH, Hughes FMR: Ecophysiology of riparian cottonwoods: stream flow dependency, water relations and restoration. Tree Physiol 2003, 23:1113-1124

4. Rood SB, Patiño S, Coombs K, Tyree MT: Branch sacrifice: cavitationassociated drought adaptation of riparian cottonwoods. Trees 2000, 14:248-257.

5. Smit BA: Selection of flood-resistant and susceptible seedlings of Populus trichocarpa Torr. \& Gray. Can J For Res 1988, 18:271-275.

6. Sakurai N: Dynamic function and regulation of apoplast in the plant body. J Plant Res 1998, 111:133-148.

7. Dietz KJ: Functions and responses of the leaf apoplast under stress. Progress in Botany 1997, 58:221-254.

8. Haslam RP, Downie AL, Raveton M, Gallardo K, Job D, Pallett KE, John P, Parry MAJ, Coleman JOD: The assessment of enriched apoplastic extracts using proteomic approaches. Ann Appl Biol 2003, 143:81-91.

9. Alvarez S, Goodger JQD, Marsh EL, Chen S, Asirvatham VS, Schachtman DP: Characterization of the maize xylem sap proteome. J Proteome Res 2006, 5:963-972.

10. Biles $\mathrm{CL}$, Martyn RD, Wilson HD: Isozymes and general proteins from various watermelon cultivars and tissue types. HortScience 1989, 24:810-812.

11. Buhtz A, Kolasa A, Arlt K, Walz C, Kehr J: Xylem sap protein composition is conserved among different plant species. Planta 2004, 219:610-618.

12. Djordjevic MA, Oakes M, Li DX, Hwang CH, Hocart CH, Gresshoff PM: The Glycine max xylem sap and apoplast proteome. J Proteome Res 2007, 6:3771-3779.

13. Floerl S, Druebert C, Majcherczyk A, Karlovsky P, Kues U, Polle A: Defence reactions in the apoplastic proteome of oilseed rape (Brassica napus var. napus) attenuate Verticillium longisporum growth but not disease symptoms. BMC Plant Biol 2008, 8:129.

14. Kehr J, Buhtz A, P G: Analysis of xylem sap proteins from Brassica napus. BMC Plant Biol 2005, 21:5-11.

15. Masuda S, Kamada H, Satoh S: Chitinase in cucumber xylem sap. Biosci Biotechnol Biochem 2001, 65:1883-1885.

16. Masuda S, Sakuta C, Satoh S: cDNA cloning of a novel lectin-like xylem sap protein and its root-specific expression in cucumber. Plant Cell Physiol 1999, 40:1177-1181.

17. Rep M, Dekker HL, Vossen JH, de Boer A, Houterman PM, Speijer D, Back JW, de Koster CG, Cornelissen JC: Mass spectrometric identification of isoforms of PR proteins in xylem sap of fungus-infected tomato. Plant Physiol 2002, 130:904-917.

18. Rep M, Dekker HL, Vossen JH, de Boer AD, Houterman PM, de Koster CG, Cornelissen BJC: A tomato xylem sap protein represents a new family of small cysteine-rich proteins with structural similarity to lipid transfer proteins. FEBS Lett 2003, 534:82-86.

19. Satoh S, lizuka C, Kikuchi A, Nakamura N, Fujii T: Proteins and carbohydrates in xylem sap from squash root. Plant Cell Physiol 1992, 33:841-847.

20. Boudart $G$, Jamet $E$, Rossignol M, Lafitte C, Borderies $G$, Jauneau A, Esquerre-Tugaye M-T, Pont-Lezica R: Cell wall proteins in apoplastic fluids of Arabidopsis thaliana rosettes: Identification by mass spectrometry and bioinformatics. Proteomics 2005, 5:212-221.

21. Biles CL, Abeles FB: Xylem sap proteins. Plant Physiol 1991, 96:597-601.

22. Dafoe NJ, Constabel CP: Proteomic analysis of hybrid poplar xylem sap. Phytochemistry 2009, 70:856-863. 
23. Diaz-Vivancos P, Rubio M, Mesonero V, Periago PM, Ros-Barcelo A, MartinezGomez P, Hernandez JA: The apoplastic antioxidant system in Prunus: response to long-term plum pox virus infection. J Exp Bot 2006, 57:3813-3824

24. Gau AE, Koutb M, Piotrowski M, Kloppstech K: Accumulation of pathogenesis-related proteins in the apoplast of a susceptible cultivar of apple (Malus domestica cv. Elstar) after infection by Venturia inaequalis and constitutive expression of PR genes in the resistant cultivar Remo. Eur J Plant Pathol 2004, 110:703-711.

25. Giavalisco P, Kapitza K, Kolasa A, Buhtz A, Kehr J: Towards the proteome of Brassica napus phloem sap. Proteomics 2006, 6:896-909.

26. Lin M-K, Lee Y-J, Lough TJ, Phinney BS, Lucas WJ: Analysis of the pumpkin phloem proteome provides functional insights into angiosperm sieve tube function. Mol Cell Proteomics 2009, 8:343-356.

27. Walz C, Giavalisco P, Schad M, Juenger M, Klose J, Kehr J: Proteomics of cucurbit phloem exudate reveals a network of defense proteins. Phytochemistry 2004, 65:1795-1804.

28. Hartung W, Radin JW, Hendrix DL: Abscisic acid movement into the apoplastic solution of water-stressed cotton leaves. Plant Physiol 1988, 86:908-913.

29. Ackerson RC: Synthesis and movement of abscisic acid in water-stressed cotton leaves. Plant Physiol 1982, 69:609-613.

30. Cornish K, Zeevaart JAD: Movement of abscisic acid into the apoplast in response to water stress in Xanthium strumarium L. Plant Physiol 1985 78:623-626.

31. Bendtsen JD, Nielsen $H$, von Heijne G, Brunak S: Improved prediction of signal peptides: SignalP 3.0. J Mol Biol 2004, 340:783-795.

32. Bendtsen JD, Kiemer L, Fausbøll A, Brunak S: Non-classical protein secretion in bacteria. BMC Microbiology 2005, 5:58.

33. Fujihara J, Yasuda T, Kunito T, Fujii Y, Takatsuka H, Moritani T, H T: Two Nlinked glycosylation sites (Asn18 and Asn106) are both required for full enzymatic activity, thermal stability, and resistance to proteolysis in mammalian deoxyribonuclease I. Biosci Biotechnol Biochem 2008, 72:3197-3205.

34. Knudsen SK, Stensballe A, Franzmann M, Westergaard UB, Otzen DE: Effect of glycosylation on the extracellular domain of the Ag43 bacterial autotransporter: enhanced stability and reduced cellular aggregation. Biochem J 2008, 412:563-577.

35. Lige $B, M a S$, van Huystee RB: The effects of the site-directed removal of $\mathrm{N}$-glycosylation from cationic peanut peroxidase on its function. Arch Biochem Biophys 2001, 386:17-24

36. O'Neill HG, Redelinghuys P, Schwager SL, Sturrock ED: The role of glycosylation and domain interactions in the thermal stability of human angiotensin-converting enzyme. Biol Chem 2008, 389:1153-1161.

37. Blom N, Gammeltoft S, Brunak S: Sequence- and structure-based prediction of eukaryotic protein phosphorylation sites. J Mol Biol 1999, 294:1351-1362.

38. Kreuzwieser J, Hauberg J, Howell KA, Carroll A, Rennenberg H, Millar AH, Whelan J: Differential response of gray poplar leaves and roots underpins stress adaptation during hypoxia. Plant Physiol 2009, 149:461-473

39. Tripepi RR, Mitchell CA: Stem hypoxia and root respiration of flooded maple and birch seedlings. Physiol Plantarum 1984, 60:567-571.

40. Kimmerer TW, Stringer MA: Alcohol dehydrogenase and ethanol in the stems of trees: Evidence for anaerobic metabolism in the vascular cambium. Plant Physiol 1988, 87:693-697.

41. Kreuzwieser J, Papadopoulou E, Rennenberg H: Interaction of flooding with carbon metabolism of forest trees. Plant Biol 2004, 6.299-306.

42. Jaeger C, Gessler A, Biller S, Rennenberg H, Kreuzwieser J: Differences in C metabolism of ash species and provenances as a consequence of root oxygen deprivation by waterlogging. J Exp Bot 2009, 60:4335-4345.

43. Kimmerer TW: Alcohol dehydrogenase and pyruvate decarboxylase activity in leaves and roots of eastern cottonwood (Populus deltoides Bartr.) and soybean (Glycine max L.). Plant Physiol 1987, 84:1210-1213.

44. Kreuzwieser J, Kuhnemann F, Martis A, Rennenberg H, Urban W: Diurnal pattern of acetaldehyde emission by flooded poplar trees. Physiol Plantarum 2000, 108:79-86

45. Kreuzwieser J, Scheerer $U$, Rennenberg H: Metabolic origin of acetaldehyde emitted by poplar (Populus tremula $\times$ P. alba) trees. J Exp Bot 1999, 50:757-765.
46. MacDonald RC, Kimmerer TW: Metabolism of transpired ethanol by eastern cottonwood (Populus deltoides Bartr.). Plant Physiol 1993, 102:173-179.

47. Telewski FW, Aloni R, Sauter JJ: Physiology of secondary tissues of Populus. In Biology of Populus. Edited by: Stettler RF, Bradshaw Jr HD, Heilman PE, Hincley TM. Ottawa, Canada: NRC Research Press; 1996:57-85.

48. Heizmann U, Kreuzwieser J, Schnitzler JP, Bruggemann N, Rennenberg H: Assimilate transport in the xylem sap of pedunculate oak (Quercus robur) saplings. Plant Biol 2001, 3:132-138.

49. Coleman HD, Yan J, Mansfield SD: Sucrose synthase affects carbon partitioning to increase cellulose production and altered cell wall ultrastructure. Proc Natl Acad Sci USA 2009, 106:13118-13123.

50. Gravatt DA, Kirby CJ: Patterns of photosynthesis and starch allocation in seedlings of four bottomland hardwood tree species subjected to flooding. Tree Physiol 1998, 18:411-417.

51. Andersson-Gunneras $S$, Mellerowicz EJ, Love J, Segerman B, Ohmiya $Y$ Coutinho PM, Nilsson P, Henrissat B, Moritz T, Sundberg B: Biosynthesis of cellulose-enriched tension wood in Populus: Global analysis of transcripts and metabolites identifies biochemical and developmental regulators in secondary wall biosynthesis. Plant J 2006, 45:144-165.

52. Ricard B, Rivoal J, Spiteri A, Pradet A: Anaerobic stress induces the transcription and translation of sucrose synthase in rice. Plant Physiol 1991, 95:669-674.

53. Albrecht $G$, Mustroph A: Localization of sucrose synthase in wheat roots: increased in situ activity of sucrose synthase correlates with cell wall thickening by cellulose deposition under hypoxia. Planta 2003, 217:252-260.

54. Biemelt S, Hajirezaei MR, Melzer M, Albrecht G, Sonnewald U: Sucrose synthase activity does not restrict glycolysis in roots of transgenic potato plants under hypoxic conditions. Planta 1999, 210:41-49.

55. Akihiro T, Umezawa T, Ueki C, Lobna BM, Mizuno K, Ohta M, Fujimura T: Genomic wide cDNA-AFLP analysis of genes rapidly induced by combined sucrose and $A B A$ treatment in rice cultured cells. FEBS Lett 2006, 580:5947-5952.

56. Tang T, Xie H, Wang Y, Lu B, Liang J: The effect of sucrose and abscisic acid interaction on sucrose synthase and its relationship to grain filling of rice (Oryza sativa L.). J Exp Bot 2009, 60:2641-2652.

57. Wang YT, Yang CY, Chen Y-T, Lin Y, Shaw J-F: Characterization of senescence-associated proteases in postharvest broccoli florets. Plant Physiol Biochem 2004, 42:663-670.

58. Schaller A, Stintzi A: Enzymes in jasmonate biosynthesis - Structure, function, regulation. Phytochemistry 2009, 70:1532-1538.

59. Rinaldi C, Kohler A, Frey P, Duchaussoy F, Ningre N, Couloux A, Wincker P, Thiec DL, Fluch S, Martin F, et al: Transcript profiling of poplar leaves upon infection with compatible and incompatible strains of the foliar rust Melampsora larici-populina. Plant Physiol 2007, 144:347-366.

60. Azaiez A, Boyle B, Levée V, A S: Transcriptome profiling in hybrid poplar following interactions with Melampsora rust fungi. Mol Plant-Microbe Interact 2009, 22:190-200.

61. Bowles DJ: Defense-related proteins in higher plants. Ann Rev Biochem 1992, 59:873-907.

62. Leah $\mathrm{R}$, Tommerup $\mathrm{H}$, Svendsen I, Mundy J: Biochemical and molecular characterization of three barley seed proteins with antifungal properties. J Biol Chem 1991, 266:1564-1573.

63. Mauch F, Mauch-Mani B, Boller T: Antifungal hydrolases in pea tissue. II. Inhibition of fungal growth by combinations of chitinase and b-1,3glucanase. Plant Physiol 1988, 88:936-942.

64. Schlumbaum A, Mauch F, Vogeli U, Boller T: Plant chitinases are potent inhibitors of fungal growth. Nature 1986, 324:365-367.

65. Doxey AC, Yaish MWF, Moffatt BA, Griffith M, McConkey BJ: Functional divergence in the Arabidopsis b-1,3-glucanase gene family inferred by phylogenetic reconstruction of expression states. Mol Biol Evol 2007, 24:1045-1055.

66. Kästner B, Tenhaken $\mathrm{R}$, Kauss $\mathrm{H}$ : Chitinase in cucumber hypocotyls is induced by germinating fungal spores and by fungal elicitor in synergism with inducers of acquired resistance. Plant J 1998, 13:447-454

67. Mauch F, Staehelin A: Functional implications of the subcellular localization of ethylene-induced chitinase and b-1,3-glucanase in bean leaves. Plant Cell 1989, 1:447-457. 
68. Salzer P, Hebe G, Reith A, Zitterell-Haid B, Stransky H, Gaschler K, Hager A: Rapid reaction of spruce cells to elicitors released from ectomycorrhizal fungus Hebeloma crustuliniforme, and inactivation of these elicitors by extracellular spruce cell inzymes. Planta 1996, 198:118-126.

69. Grenier J, Potvin C, Trudel J, Asselin A: Some thaumatin-like proteins hydrolyse polymeric $\beta-1,3-$ glucans. Plant J 1999, 19:4473-4480.

70. Trudel J, Grenier J, Potvin C, Asselin A: Several thaumatin-like proteins bind to $\beta-1,3-$ glucans. Plant Physiol 1998, 118:1431-1438.

71. Bokma E, Rozeboom HJ, Sibbald M, Dijkstra BW, Beintema JJ: Expression and characterization of active site mutants of hevamine, a chitinase from the rubber tree Hevea brasiliensis. Eur J Biochem 2002, 269:893-901.

72. Broglie KE, Gaynor JJ, Broglie RM: Ethylene-regulated gene expression: molecular cloning of the genes encoding an endochitinase from Phaseolus vulgaris. Proc Natl Acad Sci USA 1986, 83:6820-6824.

73. Petruzzelli L, Kunz C, Waldvogel R, Meins FJ, Leubner-Metzger G: Distinct ethylene- and tissue-specific regulation of $\beta$-1,3-glucanases and chitinases during pea seed germination. Planta 1999, 209:195-201.

74. Vorwerk S, Somerville S, Somerville C: The role of plant cell wall polysaccharide composition in disease resistance. Trends Plant Sci 2004, 9:203-209.

75. Bae E-K, Lee H, Lee J-S, Noh E-W, Han M-S, Choi Y-I: Molecular cloning of a peroxidase gene from poplar and its differential expression in response to stress. Tree Physiol 2006, 26:1405-1412.

76. Chittoor JM, Leach JE, White FF: Differential induction of a peroxidase gene family during infection of rice by Xanthomonas oryzae pv. oryzae. Mol Plant-Microbe Interact 1997, 10:861-871.

77. Choi HW, YJ K, Lee SC, Hong JK, Hwang BK: Hydrogen peroxide generation by the pepper extracellular peroxidase $\mathrm{CaPO} 2$ activates local and systemic cell death and defense response to bacterial pathogens. Plant Physiol 2007, 145:890-904.

78. Delannoy E, Jalloul A, Assigbetse K, Marmey P, Geiger JP, Lherminier J, Daniel JF, Martinez C, Nicole M: Activity of class III peroxidases in the defense of cotton to bacterial blight. Mol Plant-Microbe Interact 2003, 16:1030-1038

79. Kim Y-H, Yang K-S, Kim CY, Ryu S-H, Song W-K, Kwon S-Y, Lee H-S, Bang JW, Kwak S-S: Molecular cloning of peroxidase cDNAs from dehydrationtreated fibrous roots of sweetpotato and their differential expression in response to stress. J Biochem Mol Biol 2007, 41:259-265.

80. Hilaire E, A S, Young SA, Willard LH, McGee JD, Sweat T, Chittoor JM, Guikema JA, Leach JE: Vascular defense responses in rice: Peroxidase accumulation in xylem parenchyma cells and xylem wall thickening. Mol Plant-Microbe Interact 2001, 14:1411-1419.

81. Reimers PJ, Guo A, Leach JK: Increased activity of a cationic peroxidase associated with an incompatible interaction between Xanthomonas oryzae pv oryzae and Rice (Oryza sativa). Plant Physiol 1992, 99:1044-1050.

82. Young SA, Cuo A, Cuikema JA, White FF, Leach JE: Rice cationic peroxidase accumulates in xylem vessels during incompatible interactions with Xanthomonas oryzae pv oryzae. Plant Physiol 1995, 107:1333-1341

83. Christensen JH, Bauw G, Welinder KG, Van Montagu M, Boerjan W: Purification and characterization of peroxidases correlated with lignification in poplar xylem. Plant Physiol 1998, 118:125-135.

84. Christensen JH, Overney S, Rohde A, Diaz WA, Bauw G, Simon P, Van Montagu M, Boerjan W: The syringaldazine-oxidizing peroxidase PXP 3-4 from poplar xylem: cDNA isolation, characterization and expression. Plant Mol Biol 2001, 47:581-593.

85. Li Y, Kajita S, Kawai S, Katayama Y, Morohoshi M: Down regulation of an anionic peroxidase in transgenic aspen and its effect on lignin characteristics. J Plant Res 2003, 116:175-182.

86. Osakabe K, Koyama H, Kawai S, Katayama Y, Morohoshi N: Molecular cloning and the nucleotide sequences of two novel cDNAs that encode anionic peroxidases of Populus kitakamiensis. Plant Sci 1994, 103:167-175.

87. Osakabe K, Koyama H, Kawai S, Katayama Y, Morohoshi N: Molecular cloning of two tandemly arranged peroxidase genes from Populus kitakamiensis and their differential regulation in the stem. Plant Mol Biol 1995, 28:677-689.

88. Sasaki S, Baba K, Nishida T, Tsutsumi Y, Kondo R: The cationic cell-wallperoxidase having oxidation ability for polymeric substrate participates in the late stage of lignification of Populus alba L. Plant Mol Biol 2006, 62:797-807.
89. Sasaki S, Nishida T, Tsutsumi Y, Kondo R: Lignin dehydrogenative polymerization mechanism: a poplar cell wall peroxidase directly oxidizes polymer lignin and produces in vitro dehydrogenative polymer rich in b-O-4 linkage. FEBS Lett 2004, 562:197-201.

90. Sasaki S, Shimizu M, Wariishi H, Tsutsumi Y, Kondo R: Transcriptional and translational analyses of poplar anionic peroxidase isoenzymes. J Wood Sci 2007, 53:427-435.

91. Takeuchi M, Takabe K, Minoru Fujita M: Immunolocalization of an anionic peroxidase in differentiating poplar xylem. J Wood Sci 2005, 51:317-322.

92. Bernards MA, Fleming WD, Llewellyn DB, Priefer R, Yang X, Sabatino A, Plourde GL: Biochemical characterization of the suberization-associated anionic peroxidase of potato. Plant Physiol 1999, 121:135-145.

93. Czaninski Y, Sachot RM, Catesson AM: Cytochemical localization of hydrogen peroxide in lignifying cell walls. Ann Bot 1993, 72:547-550.

94. Ros Barcelo A: Hydrogen peroxide production is a general property of the lignifying xylem from vascular plants. Ann Bot 1998, 82:97-103.

95. Ros Barcelo A: Xylem parenchyma cells deliver the $\mathrm{H}_{2} \mathrm{O}_{2}$ necessary for lignification in differentiating xylem vessels. Planta 2005, 220:747-756.

96. Ros Barcelo A, Gomez-Ros LV, Ferrer MA, Hernandez JA: The apoplastic antioxidant enzymatic system in the wood-forming tissues of trees. Trees 2006, 20:145-156.

97. Bolwell GP, Wojtaszek P: Mechanisms for the generation of reactive oxygen species in plant defence - a broad perspective. Physiol Mol Plant Pathol 1997, 51:347-366.

98. Kotchoni S, Gachomo EW: The reactive oxygen species network pathways: an essential prerequisite for perception of pathogen attack and the acquired disease resistance in plants. J Biosci 2006, 31:389-404.

99. Levine A, Tenhaken $\mathrm{R}$, Dixon $\mathrm{R}$, Lamb $\mathrm{C}: \mathrm{H}_{2} \mathrm{O}_{2}$ from the oxidative burst orchestrates the plant hypersensitive disease resistance response. Cell 1994, 79:583-593.

100. Mellersh DG, Foulds IV, Higgins VJ, $\mathrm{CM} \mathrm{H}: \mathrm{H}_{2} \mathrm{O}_{2}$ plays different roles in determining penetration failure in three diverse plant-fungal interactions. Plant J 2002, 29:257-268

101. Vanacker H, Harbinson J, Ruisch J, Carver TLW, Foyer CH: Antioxidant defences of the apoplast. Protoplasma 1998, 205:129-140.

102. Mittler R: Oxidative stress, antioxidants and stress tolerance. Trends Plant Sci 2002, 7:405-410.

103. Moller IM, Jensen PE, Hansson A: Oxidative modification to cellular components in plants. Annu Rev Plant Biol 2007, 58:459-481.

104. Pavet V, Olmos E, Kiddle G, Mowla S, Kumar S, Antoniw J, Alvarez ME, Foyer CH: Ascorbic acid deficiency activates cell death and disease resistance responses in Arabidopsis. Plant Physiol 2005, 139:1291-1303.

105. Montricharda F, Alkhalfiouib F, Yano F, Vensel WH, Hurkman WJ Buchanan BB: Thioredoxin targets in plants: The first 30 years. $J$ Proteomics 2009, 72:452-474.

106. Ishikawa T, Shigeoka S: Recent advances in ascorbate biosynthesis and the physiological significance of ascorbate peroxidase in photosysnthesizing organisms. Biosci Biotechnol Biochem 2008, 72:1143-1154

107. Pignocchi $\mathrm{C}$, Foyer $\mathrm{CH}$ : Apoplastic ascorbate metabolism and its role in the regulation of cell signaling. Curr Opin Plant Biol 2003, 6:379-389.

108. Plomion C, Lalanne C, Claverol S, Meddour H, Kohler A, Bogeat-Triboulot MB, Barre A, Le Provost G, Dumazet H, Jacob D, et al: Mapping the proteome of poplar and application to the discovery of drought-stress responsive proteins. Proteomics 2006, 6:6509-6527.

109. Srivastava V, Schinkel H, Witzell J, Hertzberg M, Torp M, Srivastava MK, Karpinska B, Melzer M, Wingsle G: Downregulation of high-isoelectricpoint extracellular superoxide dismutase mediates alterations in the metabolism of reactive oxygen species and developmental disturbances in hybrid aspen. Plant J 2006, 49:135-148.

110. Thornalley PJ: The glyoxalase system: new developments towards functional characterization of a metabolic pathway fundamental to biological life. Biochem J 1990, 269:1-11.

111. Yadav SK, Singla-Pareek SL, Ray M, Reddy MK, Sopory SK: Methylglyoxal levels in plants under salinity stress are dependent on glyoxalase I and glutathione. Biochem Biophysical Res Com 2005, 337:61-67.

112. Edwards R, Dixon DP, Walbot V: Plant glutathione S-transferases: enzymes with multiple functions in sickness and health. Trends Plant Sci 2000 5:193-198 
113. Jiang $L$, Yang $H$ : Prometryne-induced oxidative stress and impact on antioxidant enzymes in wheat. Ecotoxicol Environ Saf 2009, 72:1687-1693.

114. Yin $X L$, Jiang L, Song NH, Yang H: Toxic reactivity of wheat (Triticum aestivum) plants to herbicide isoproturon. J Agric Food Chem 2008, 56:4825-4831

115. Harmer SL, Hogenesch JB, Straume M, Chang H-S, Han B, Zhu T, Wang X, Kreps JA, Kay SA: Orchestrated transcription of key pathways in Arabidopsis by the circadian clock. Science 2000, 290:2110-2113.

116. Kehr J, Rep M: Protein extraction from xylem and phloem sap. In Plant Proteomics Methods and Protocols. Volume 355. Edited by: Thiellement $\mathrm{H}_{\text {, }}$ Zivy M, Damerval C, Méchin V. Totowa, New Jersey: Humana Press; 2007:27-35.

117. Hurkman WJ, Tanaka CK: Solubilization of plant membrane proteins for analysis by two-dimensional gel electrophoresis. Plant Physiol 1986, 81:802-806.

118. Pechanova O, Stone WD, Monroe W, Nebeker TE, Klepzig KD, Yuceer C: Global and comparative protein profiles of the pronotum of the southern pine beetle, Dendroctonus frontalis. Insect Mol Biol 2008, 17:261-277.

119. Nanduri B, Lawrence ML, Vanguri S, Pechan T, Burgess SC: Proteomic analysis using an unfinished bacterial genome: the effect of subminimum inhibitory concentrations of antibiotics on Mannheimia haemolytica virulence factor expression. Proteomics 2005, 5:4852-4863.

120. Ashburner M, Ball CA, Blake JA, Botstein D, Butler H, Cherry JM, Davis AP, Dolinski K, Dwight SS, Eppig JT, et al: Gene Ontology: Tool for the unification of biology. The Gene Ontology Consortium. Nat Genet 2000, 25:25-29.

121. Nielsen $H$, Engelbrecht J, Brunak S, von Heijne G: Identification of prokaryotic and eukaryotic signal peptides and prediction of their cleavage sites. Protein Eng 1997, 10:1-6.

122. Yuceer C, Land SB Jr, Kubiske ME, Harkess RL: Shoot morphogenesis associated with flowering in Populus deltoides (SALICACEAE). Amer J Bot 2003, 90:196-206.

123. Wan CY, Wilkins TA: A modified hot borate method significantly enhances the yield of high-quality RNA from cotton (Gossypium hirsutum L.). Anal Biochem 1994, 223:7-12.

124. R Development Core Team: R: A language and environment for statistical computing. Vienna, Austria: R Foundation for Statistical Computing; 2008.

125. Gentleman RC, Carey VJ, Bates DM, Bolstad B, Dettling M, Dudoit S, Ellis B, Gautier L, Ge Y, Gentry J, et al: Bioconductor: open software development for computational biology and bioinformatics. Genome Biology 2004, 5: R80.

126. MacDonald JW: Affycoretools: Functions useful for those doing repetitive analyses with Affymetrix GeneChips. R package version 11412005.

127. Wu Z, Irizarry RA: Stochastic models inspired by hybridization theory for short oligonucleotide arrays. J Comput Biol 2005, 12:882-893.

128. Smyth GK: Limma: linear models for microarray data. In Bioinformatics and Computational Biology Solutions using $R$ and Bioconductor. Edited by: Gentleman R, Carey V, Dudoit S, Irizarry R, Huber W. New York: Springer; 2005:397-420.

129. Smyth GK: Linear models and empirical Bayes methods for assessing differential expression in microarray experiments. Statist Appl in Gen Mol Biology 2004, 3(1):Article 3.

130. Langfelder $P$, Zhang B, Horvath S: Defining clusters from a hierarchical cluster tree: the Dynamic Tree Cut library for R. Bioinformatics 2008, 24:719-720.

131. Hsu C-Y, Liu Y, Luthe DS, Yuceer C: Poplar FT2 shortens the juvenile phase and promotes seasonal flowering. Plant Cell 2006, 18:1846-1861.

132. Larson PR, Isebrands JG: The plastochron index as applied to developmental studies of cottonwood. Can J For Res 1971, 1:1-11.

133. Boyle B, Levée V, Hamel L-P, Nicole M-C, Séguin A: Molecular and histochemical characterization of two distinct poplar Melampsora leaf rust pathosystems. Plant Biology 2010, 12:364-376.

134. Rutledge RG, Stewart D: A kinetic-based sigmoidal model for the polymerase chain reaction and its application to high-capacity absolute quantitative real-time PCR. BMC Biotechnol 2008, 8:47.

135. Livak KJ, Schmittgen TD: Analysis of relative gene expression data using real-time quantitative PCR and $2^{-D D C t}$ method. Methods 2001, 25:402-408

136. Vandesompele J, De Preter K, Pattyn F, Poppe B, Van Roy N, De Paepe A, Speleman F: Accurate normalization of real-time quantitative RT-PCR data by geometric averaging of multiple internal control genes. Genome Biol 2002, 3:research 0034.

137. Destefano-Beltrán L, Knauber D, Huckle L, Suttle JC: Effects of postharvest storage and dormancy status on $A B A$ content, metabolism, and expression of genes involved in $A B A$ biosynthesis and metabolism in potato tuber tissues. Plant Mol Biol 2006, 61:687-697.

138. Srivastava LM: Plant Growth and Development. Hormones and Environment. San Diego, CA, USA: Academic Press; 2002

139. Magneschi L, Perata P: Rice germination and seedling growth in the absence of oxygen. Ann Bot 2009, 103:181-196.

140. Narsai R, Howell KA, Carroll A, Ivanova A, Millar AH, Whelan J: Defining core metabolic and transcriptomic responses to oxygen availability in rice embryos and young seedlings. Plant Physiol 2009, 151:306-322.

141. Miranda M, Ralph SG, Mellway R, White R, Heath MC, Bohlmann J, Constabel CP: The transcriptional response of hybrid poplar (Populus trichocarpa $\times$ P. deltoides) to infection by Melampsora medusae leaf rust involves induction of flavonoid pathway genes leading to the accumulation of proanthocyanidins. Mol Plant-Microbe Interact 2007 20:816-831.

142. Street NR, Skogstrom O, Sjodin A, Tucker J, Rodrıguez-Acosta R, Nilsson P, Jansson S, Taylor G: The genetics and genomics of the drought response in Populus. Plant J 2006, 48:321-341.

doi:10.1186/1471-2164-11-674

Cite this article as: Pechanova et al: Apoplast proteome reveals that extracellular matrix contributes to multistress response in poplar. $B M C$ Genomics 2010 11:674.

\section{Submit your next manuscript to BioMed Central and take full advantage of:}

- Convenient online submission

- Thorough peer review

- No space constraints or color figure charges

- Immediate publication on acceptance

- Inclusion in PubMed, CAS, Scopus and Google Scholar

- Research which is freely available for redistribution

Submit your manuscript at www.biomedcentral.com/submit
C Biomed Central 